Article

\title{
Phase Voltage-Oriented Control of a PMSG Wind Generator for Unity Power Factor Correction
}

\author{
Ming-Fa Tsai *, Chung-Shi Tseng and Bor-Yuh Lin \\ Department of Electrical Engineering, Minghsin University of Science and Technology, 1, Xinxing Rd., Xinfeng, \\ Hsinchu 30401, Taiwan; cstseng@must.edu.tw (C.-S.T.); lordben0033@gmail.com (B.-Y.L.) \\ * Correspondence: mftsai@must.edu.tw; Tel.: +886-3-5593142 (ext. 3070); Fax: +886-3-5573-895
}

Received: 26 August 2020; Accepted: 22 October 2020; Published: 30 October 2020

\begin{abstract}
This paper presents the power factor control of a permanent magnet synchronous wind generator (PMSG) wind turbine using a phase voltage-oriented control (PVOC) scheme, which is different from the conventional rotor flux-oriented control (RFOC) method and without using a rotor position sensor or sensorless estimator. The proposed control system is operated in two separately synchronously rotating $d-q$ frames. One is for a phase-locked loop (PLL) and the other is for the PVOC current control loop. A PI controller functioned as a low-pass filter in the PLL loop is designed for extracting the phase voltage angle for the coordinate transformation between the stationary $\alpha-\beta$ frame and the synchronously rotating $d-q$ frame in the PVOC control loop. The $d-q$ modeling of the PMSG with the three-phase voltage vector aligned on the $d$-axis is then derived and based on which an another PI controller followed by decoupling control is designed, so that the three-phase currents are in phase with the three-phase output voltages of the wind generator for unity power factor correction. The simulation results in PSIM show the performance of the proposed control system which is also experimentally verified by using a TI TMS320F28335 digital control chip.
\end{abstract}

Keywords: PMSG wind generator; phase-locked loop; phase voltage-oriented control; power factor correction

\section{Introduction}

Global warming and air pollution have received much attention in the world over the past two decades. The development of renewable energies is one of the methods to solve the problems. Among renewable energies, wind energy, which can be extracted through wind turbine generators and converted by using power electronics and control technology, has been one of the progressive research and development field because of the rapid growing of the power electronics and semiconductor technology [1-3]. Traditionally, to increase the wind energy conversion efficiency, it is necessary to employ maximum power point tracking (MPPT) control techniques for extracting the maximum power from the wind energy under various wind speed conditions. Up to now, there have been many MPPT algorithms developed, which can be divided into tip speed ratio (TSR), power signal feedback (PSF), and hill climb search (HCS) methods [4-14]. Among them, TSR control method requires the knowledge of rotor speed and wind speed, which can be given either by measured or estimated, to regulate the wind generator rotation speed so that the system keeps an optimal TSR value for the maximum power efficiency [4,5]. PSF control method tracks the maximum power curve with respect to the wind generator rotation speed to deliver maximum power [6,7]. HCS control method searches for the maximum power point of the wind generator continuously based on the locality of the operating point [8-14]. 
In addition to employing the MPPT control for extracting the maximum power of the wind generator under various wind speed conditions, power factor correction is also required in some cases to reduce the ohmic power loss due to the high impedance of a wind turbine and to mitigate the audible noise issue produced by the wind generator due to low power factor especially for a small vertical-axis wind turbine which might hinder its use in urban environment $[15,16]$. Rotor flux-oriented control (RFOC) strategy, which is widely used in the PMSG wind generator systems, will result in relatively low power factor, especially in the rated load or overload operation [17].

Over the past decade, research on the unit power factor control of PMSG wind generators has been reported to solve the abovementioned power loss and audible noise problems. The adopted control methods depend on the employed topology structure for the PMSG wind generators. In [15], a VIENNA rectifier with buck topology is presented which can improve the overall power transfer with power factor correction and MPPT control in a low power wind turbine in contrast to the traditional 6-diode rectifier. However, the disadvantage is the high number of semiconductors on the converter topology. In [16], a $1.5 \mathrm{~kW}$ vertical-axis PMSG wind turbine generator charger is presented using a three-phase PWM rectifier followed by a step-down dc-dc converter with current self-control strategy for both the power factor correction to mitigate the audible noise and the maximum power point tracking without using voltage sensors. An improved technology using modified VIENNA rectifier is also reported in [18] to give an enhanced power factor with lower line current total harmonic distortion. In [19], a three-phase PWM rectifier of the PMSG based on three single-phase rectifiers is presented so as to provide unity power factor and low harmonic contents of the generator currents. As compared to conventional three-phase PWM controlled inverters, this rectifier has several advantages including robustness due to the absence of controlled switches in the same leg, the usage of switches with the source terminals connected to the same point, and reduction of switching losses. Therefore, it can simplify the command circuit employing one cycle control (OCC). However, the disadvantage is the high number of active semiconductors. In [20], a unity power factor control technology is applied to a PMSG wind generator on the basis of RFOC control by calculating the stator current using the generator parameters. But the calculation of the solution is an approximation, so the power factor is near unity. In [21], a synchronous PI current control technique is presented for a three-phase power factor correction rectifier of PMSG wind generators. The scheme has the advantage of less number of active switching devices and improving the reliability as compared to conventional PWM rectifiers. But, it also uses RFOC method which might need a rotor position sensor.

A novel approach for unity power factor correction of a PMSG wind generator is proposed in this paper by using phase voltage-oriented control (PVOC). In this scheme the output line-to-line voltages of the PMSG are measured to extract the phase angle of line voltage vector by using a phase-locked loop (PLL) scheme. After the phase angle is locked, the phase angle of the phase voltage then can be obtained and used for the coordinate transformation in the PVOC current control loop without using the PMSG rotor position sensor. The unity power factor control of PMSG can be implemented by regulating the stator current vector in synchronously $d-q$ rotating frame. The controller design is conducted firstly by PSIM simulation tool and is then experimentally verified by using a TI TMS320F28335 digital control chip.

This paper is organized as follows. Modeling of a PMSG wind turbine generator with three-phase variables is described in Section 2. The PLL scheme to extract the phase angle and the PVOC current control for unity power factor correction of the system is analyzed in Section 3 and the simulation and the experimental results are presented in Section 4. Finally, the conclusion is in Section 5. 


\section{Modeling of the PMSG Wind Turbine Generator}

As shown in Figure 1, the simplified structure of a PMSG wind generator can be divided into the PMSG and the wind turbine parts. There are two types of PMSG modeling. One is in the three-phase $a-b-c$ stationary frame for simulation analysis, and the other one is in the synchronously rotating $d-q$ frame for the PVOC current controller design which will be described in the next section. The modeling of the PMSG in the three-phase $a-b$-c stationary frame, which is a combination of circuit- and equation-based models, is described as follows. The three-phase stator voltage with respect to the generator neutral point $n$ in Figure 1 is given as

$$
\left[\begin{array}{l}
v_{a} \\
v_{b} \\
v_{c}
\end{array}\right]=\frac{d}{d t}\left[\begin{array}{l}
\psi_{a} \\
\psi_{b} \\
\psi_{c}
\end{array}\right]-R_{s}\left[\begin{array}{c}
i_{a} \\
i_{b} \\
i_{c}
\end{array}\right]
$$

where $R_{S}$ is the stator resistance and the three-phase stator flux linkage is

$$
\left[\begin{array}{l}
\psi_{a} \\
\psi_{b} \\
\psi_{c}
\end{array}\right]=\left[\begin{array}{ccc}
L_{a a} & L_{a b} & L_{a c} \\
L_{b a} & L_{b b} & L_{b c} \\
L_{c a} & L_{c b} & L_{c c}
\end{array}\right]+\psi_{r}\left[\begin{array}{c}
\cos \theta_{r} \\
\cos \left(\theta_{r}-\frac{2 \pi}{3}\right) \\
\cos \left(\theta_{r}+\frac{2 \pi}{3}\right)
\end{array}\right]
$$

where $\psi_{r}$ is the rotor flux linkage which is considered as a constant, $\theta_{r}$ is the rotor electrical angle, the mutual inductances are given as

$$
L_{a b}=L_{b a}=L_{b c}=L_{c b}=L_{c a}=L_{a c}=-\frac{L_{m}}{2}
$$

and the self-inductance in each phase is

$$
L_{a a}=L_{b b}=L_{c c}=L_{l s}+L_{m}
$$

where $L_{l s}$ is the stator leakage inductance. All symbols are listed in the Nomenclature at the end of this paper. Under the three-phase balanced condition $\left(i_{a}+i_{b}+i_{c}=0\right)$, substituting (2)-(4) into (1), yields

$$
\left[\begin{array}{c}
v_{a} \\
v_{b} \\
v_{c}
\end{array}\right]=\left[\begin{array}{c}
e_{a} \\
e_{b} \\
e_{c}
\end{array}\right]-L_{s}\left[\begin{array}{c}
\frac{d i_{a}}{d t} \\
\frac{d b_{b}}{d t} \\
\frac{d c_{c}}{d t}
\end{array}\right]-R_{s}\left[\begin{array}{c}
i_{a} \\
i_{b} \\
i_{c}
\end{array}\right]
$$

where $L_{s}$ is called the stator inductance written as

$$
L_{s}=L_{l s}+\frac{3}{2} L_{m}
$$

and $e_{a}, e_{b}, e_{c}$ can be seen as the electromotive force (emf) in each phase and written as

$$
\left[\begin{array}{c}
e_{a} \\
e_{b} \\
e_{c}
\end{array}\right]=-\omega_{r} \psi_{r}\left[\begin{array}{c}
\sin \theta_{r} \\
\sin \left(\theta_{r}-\frac{2 \pi}{3}\right) \\
\sin \left(\theta_{r}+\frac{2 \pi}{3}\right)
\end{array}\right]
$$

where $\omega_{r}$ is the rotor electrical speed. The relationship between the rotor electrical angle and the rotor electrical speed is expressed as

$$
\theta_{r}=\int \omega_{r} d t+\theta_{r 0}
$$


where $\theta_{r 0}$ is the initial angle position of the rotor. By means of power conservation principle, the generator torque can be written as

$$
T_{e}=\frac{e_{a} i_{a}+e_{b} i_{b}+e_{c} i_{c}}{\omega_{m}}
$$

where $\omega_{m}$ is the generator's mechanical speed, which is relative to the rotor electrical speed by

$$
\omega_{m}=\frac{2}{P} \omega_{r}
$$

where $P$ is the magnet pole number of the rotor. Substituting (7) and (10) into (9) yields

$$
T_{e}=\frac{-P}{2} \psi_{r}\left[i_{a} i_{b} i_{c}\right]\left[\begin{array}{c}
\sin \theta_{r} \\
\sin \left(\theta_{r}-\frac{2 \pi}{3}\right) \\
\sin \left(\theta_{r}+\frac{2 \pi}{3}\right)
\end{array}\right]
$$

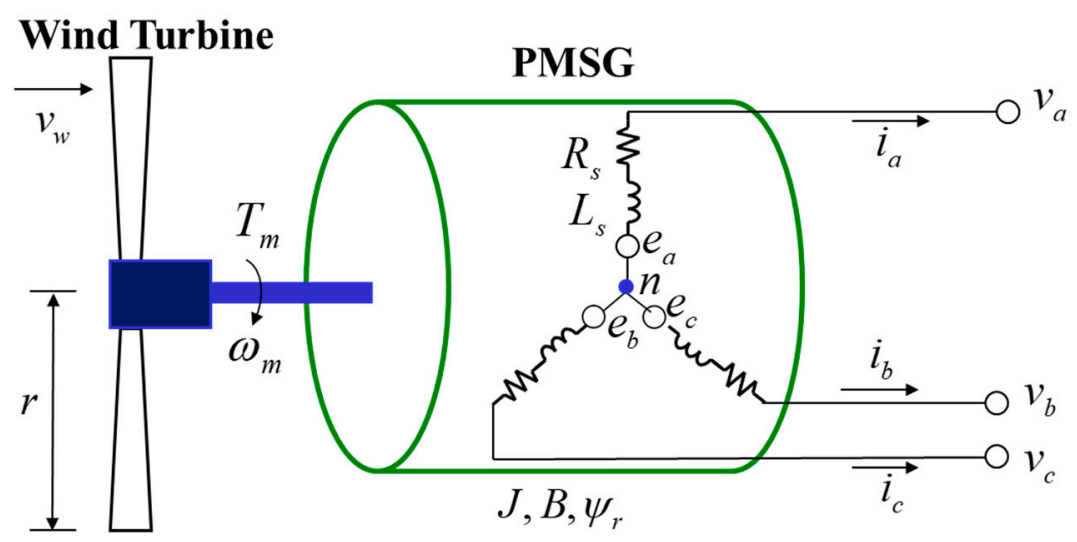

Figure 1. The permanent magnet synchronous generator (PMSG) wind turbine simplified structure.

From the Newton's 2nd motion law, the generator rotation speed equation relative to the torque can be expressed by

$$
T_{m}-T_{e}=J \frac{d \omega_{m}}{d t}+B \omega_{m}
$$

where $T_{m}$ is the wind turbine mechanical torque generated by the wind, $J$ is the moment inertia, and $B$ is the viscous coefficient of the generator. Figure 2 shows the model construction of the PMSG generator in PSIM using the parameters shown in Table 1. The model consists of an electrical part to produce the three-phase currents based on (5), an electro-mechanical part to produce the generator torque based on (11), a mechanic-to-electrical part to produce the electromotive force based on (7), and a mechanical part to produce the generator speed based on (12). 


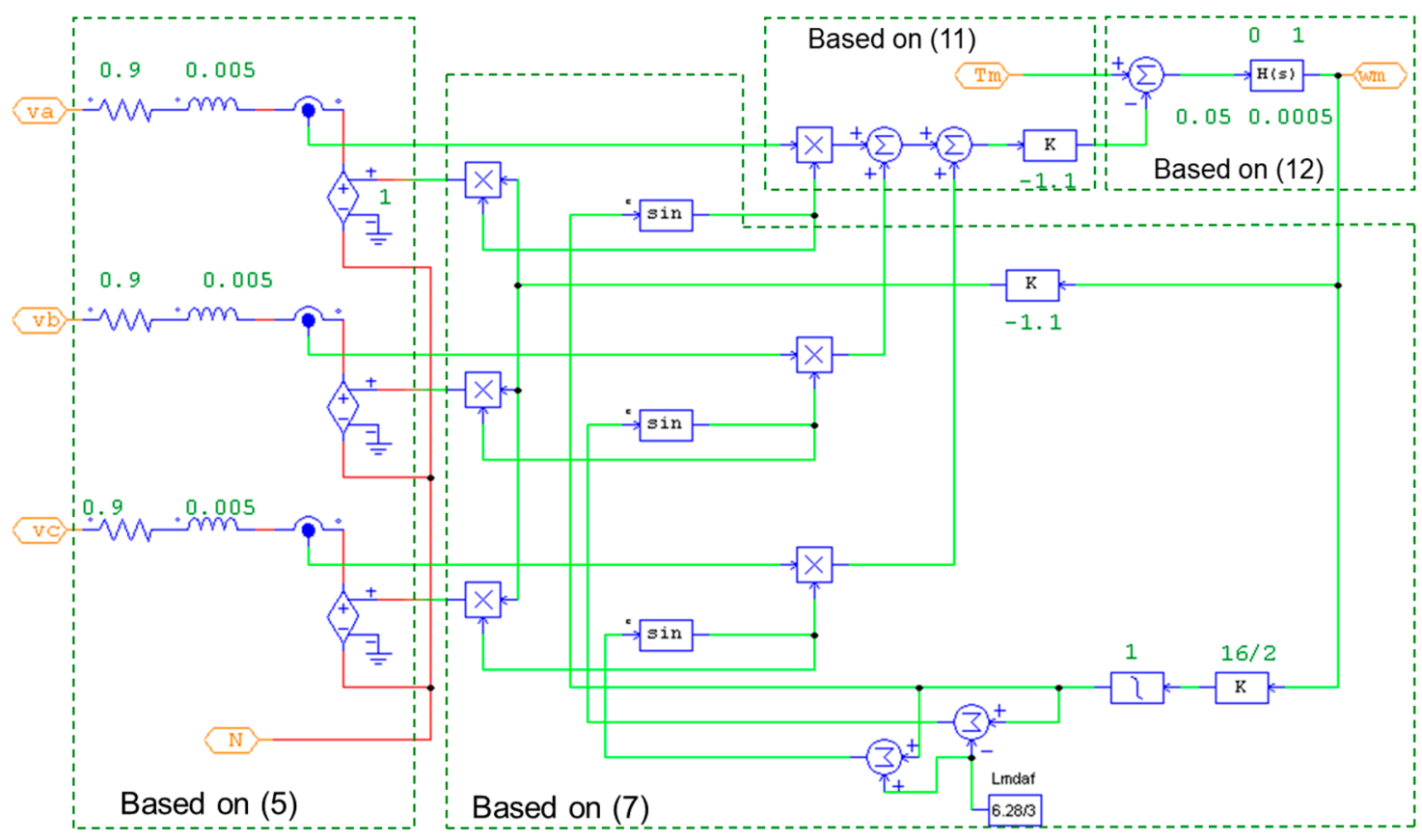

Figure 2. The PMSG model constructed in PSIM.

Table 1. PMSG parameters.

\begin{tabular}{cccc}
\hline$R_{s}$ & $0.9 \Omega$ & $B$ & $0.0005 \mathrm{Nm} / \mathrm{rad} / \mathrm{s}$ \\
\hline$L_{s}$ & $0.005 \mathrm{H}$ & $P$ & 16 \\
\hline$J$ & $0.05 \mathrm{Nm} / \mathrm{rad} / \mathrm{s}^{2}$ & $\psi_{r}$ & 0.1375 Weber \\
\hline
\end{tabular}

The input to the PMSG model is the wind turbine mechanical torque, $T_{m}$, which is relative to the wind turbine's power, $P_{w t}$, by

$$
T_{m}=\frac{P_{w t}}{\omega_{m}}
$$

and the wind turbine's power is written as

$$
P_{w t}=\frac{C_{p}(\lambda)}{2} \rho \pi r^{2} v_{w}^{3}
$$

where $\rho$ is the air density, $r$ is either the blade length of a horizontal-axis wind turbine or the rotation radius of a vertical-axis wind turbine, $v_{w}$ is the wind speed, and $C_{p}(\lambda)$ is the wind turbine power efficiency for a fixed-blade turbine and is a function of the tip speed ratio which is defined as

$$
\lambda=\frac{r \omega_{m}}{v_{w}}
$$

The PMSG wind turbine PSIM model by connecting the constructed PMSG model and the wind turbine modeling in (13)-(15) is shown in Figure 3a, in which a $C_{p}-\lambda$ look-up table is like a hill curve shown in Figure $3 \mathrm{~b}$. The PMSG wind turbine PSIM model block will be used for the simulation analysis in the following sections. 


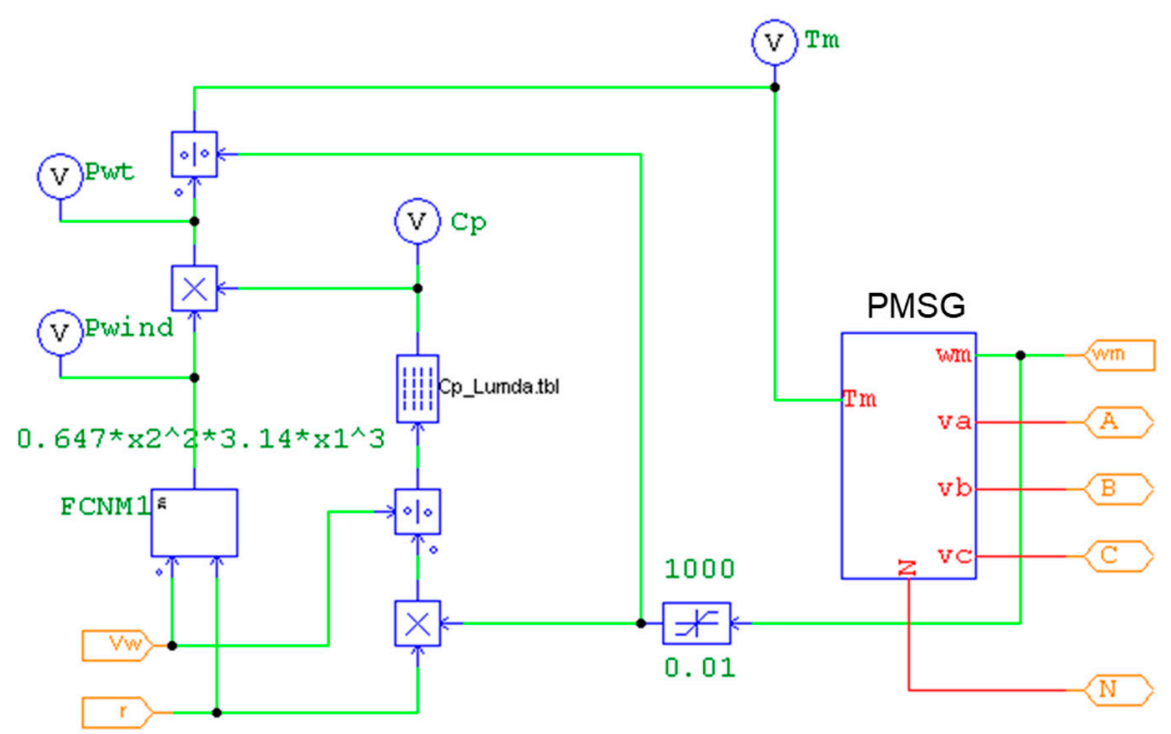

(a)

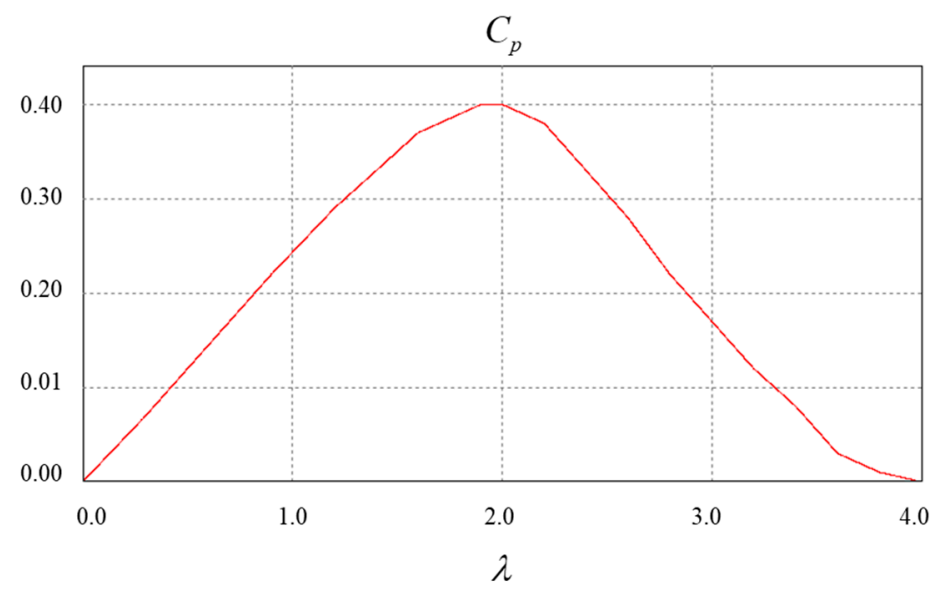

(b)

Figure 3. (a) The PMSG wind generator PSIM model; (b) The $C_{p}-\lambda$ curve.

\section{The PVOC Current Control Design}

Figure 4 shows the system block diagram of the proposed phase voltage-oriented control (PVOC) of a PMSG wind generator with unity power factor correction. The system is operated in two separately rotating $d-q$ frames. One is for a phase-locked loop (PLL) and the other is for the PVOC current control loop. As the neutral point of the Y-connected generator is hidden and unavailable, the phase voltage of the wind generator cannot be obtained directly. Therefore, the PLL block is firstly used to extract the line voltage angle, and then the phase voltage angle can be obtained by a phase shift of 30 degrees. In the PLL loop, a PI controller functioned as a low pass filter is designed for extracting the phase-voltage angle for the coordinate transformation between the stationary $\alpha-\beta$ frame and the synchronously rotating $d-q$ frame in the PVOC current control loop. The $d-q$ modeling of the PMSG with the three-phase voltage vector aligned on the $d$-axis is then derived and based on which an another PI controller followed by decoupling control is designed, so that the three-phase currents are in phase with the three-phase output voltages of the wind generator. The PLL scheme and the PVOC current control of the wind generator are described as follows. 


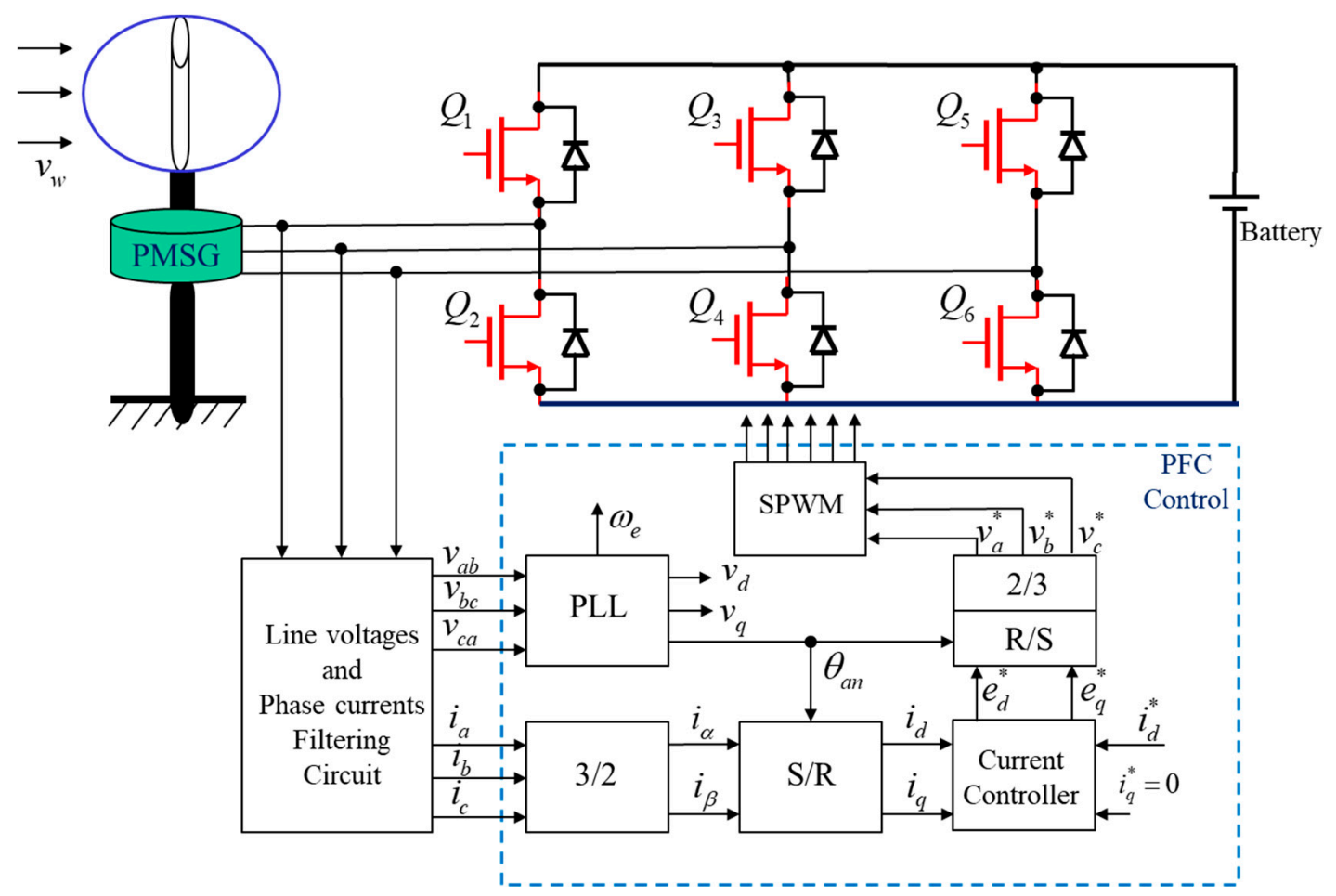

Figure 4. Block diagram of the proposed PVOC control of a PMSG wind generator.

\subsection{The PLL Scheme}

The inputs to the PLL loop, which is operated in a rotating $d-q$ frame, are the three-phase line-to-line voltages. Let the wind generator line voltage vector be $v_{l-l}$ in which the three-phase line-to-line voltage components are written as

$$
\left[\begin{array}{c}
v_{a b} \\
v_{b c} \\
v_{c a}
\end{array}\right]=\left[\begin{array}{c}
V_{m} \cos \left(\omega_{e} t+\phi\right) \\
V_{m} \cos \left(\omega_{e} t+\phi-\frac{2 \pi}{3}\right) \\
V_{m} \cos \left(\omega_{e} t+\phi+\frac{2 \pi}{3}\right)
\end{array}\right]=\left[\begin{array}{c}
V_{m} \cos \theta_{a b} \\
V_{m} \cos \left(\theta_{a b}-\frac{2 \pi}{3}\right) \\
V_{m} \cos \left(\theta_{a b}+\frac{2 \pi}{3}\right)
\end{array}\right]
$$

where $V_{m}$ is the line voltage amplitude, $\omega_{e}$ is the angular frequency, $\phi$ is the phase angle, and $\theta_{a b}$ is the $v_{a b}$ line voltage argument. Figure 5 shows the geometric diagram of the line voltage vector in the stationary $\alpha-\beta$ frame and synchronously rotating $d-q$ frame with the Clarke and Park transformation given by (17) and (18), respectively.

$$
\begin{gathered}
{\left[\begin{array}{c}
v_{\alpha} \\
v_{\beta}
\end{array}\right]=\left[\begin{array}{ccc}
1 & 0 & 0 \\
0 & \frac{1}{\sqrt{3}} & \frac{-1}{\sqrt{3}}
\end{array}\right]\left[\begin{array}{c}
v_{a b} \\
v_{b c} \\
v_{c a}
\end{array}\right]} \\
{\left[\begin{array}{c}
v_{d} \\
v_{q}
\end{array}\right]=\left[\begin{array}{cc}
\cos \theta_{e} & \sin \theta_{e} \\
-\sin \theta_{e} & \cos \theta_{e}
\end{array}\right]\left[\begin{array}{c}
v_{\alpha} \\
v_{\beta}
\end{array}\right]}
\end{gathered}
$$




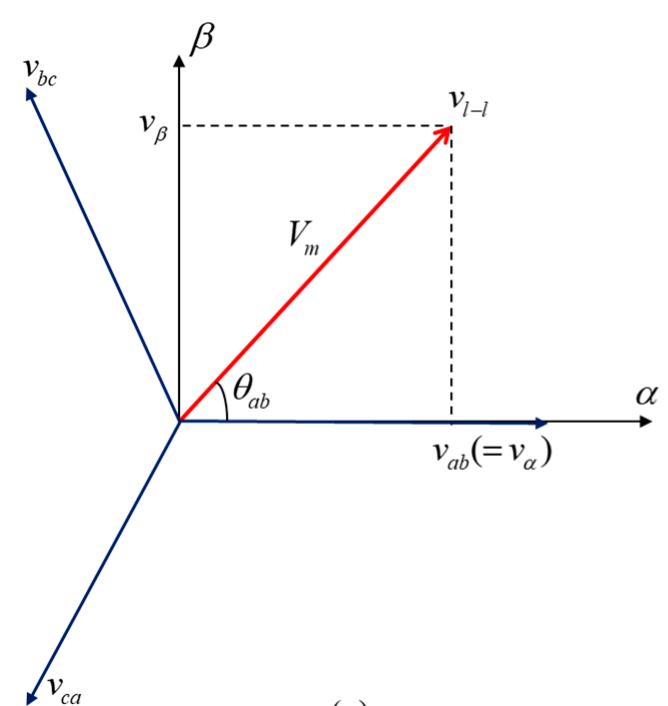

(a)

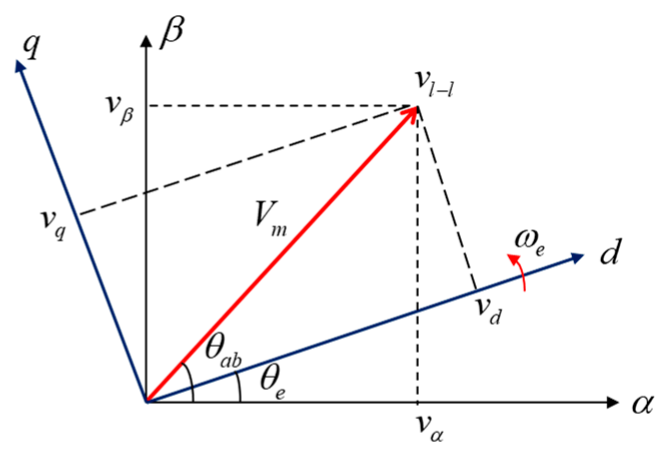

(b)

Figure 5. The geometric relationship of the line voltage vector: (a) stationary frame; (b) synchronous $d-q$ frame.

The block diagram of the employed PLL scheme is shown in Figure 6, which is composed of a phase detector (PD), a low-pass filter (LPF), and a voltage-controlled oscillator (VCO) where $\omega_{c}$ is the center frequency of the $\mathrm{VCO}$ as a feed-forward parameter dependent on the range of frequency to be detected [22]. Substituting (16) into (17) yields

$$
\left[\begin{array}{c}
v_{\alpha} \\
v_{\beta}
\end{array}\right]=\left[\begin{array}{l}
V_{m} \cos \theta_{a b} \\
V_{m} \sin \theta_{a b}
\end{array}\right]
$$

and then substituting (19) into (18) yields

$$
\left[\begin{array}{c}
v_{d} \\
v_{q}
\end{array}\right]=\left[\begin{array}{c}
V_{m} \cos \left(\theta_{a b}-\theta_{e}\right) \\
V_{m} \sin \left(\theta_{a b}-\theta_{e}\right)
\end{array}\right]
$$

As $\theta_{e} \approx \theta_{a b}$, the phase is locked. Then, the second row of (20) can be rewritten as

$$
v_{q}=V_{m}\left(\theta_{a b}-\theta_{e}\right)
$$




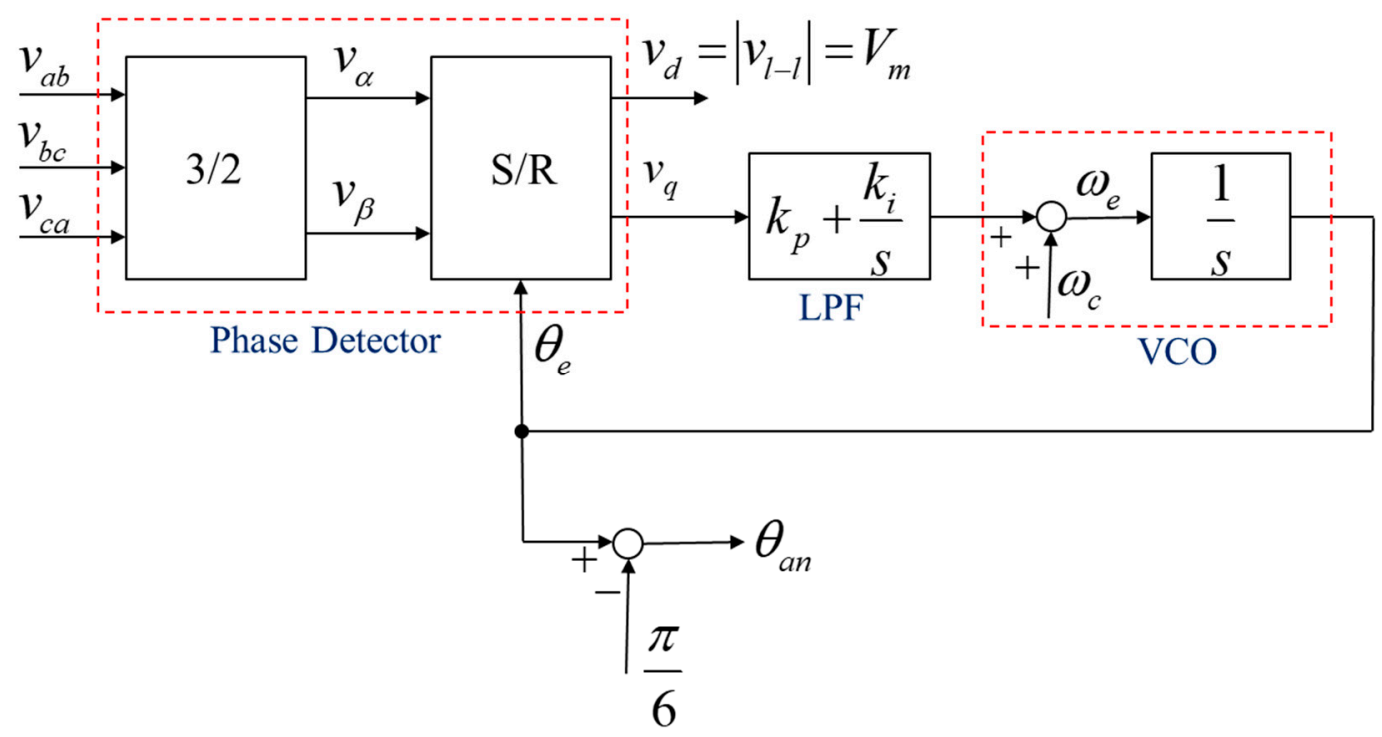

Figure 6. The PLL scheme based on Park transformation to extract the phase voltage angle.

Thus, the $S / R$ block in the phase detector of Figure 6 is functioned as a phase subtracter or a phase comparator. As $\theta_{e}=\theta_{a b}, v_{q}$ is equal to zero. This means the line voltage vector $v_{l-l}$ is aligned to the $d$-axis. To design the PI controller of the phase-locked loop, the transfer-function block diagram can be plotted as shown in Figure 7. The transfer function from the input $\theta_{e}^{*}$ the output $\theta_{e}$ is

$$
T(s)=\frac{\Theta_{e}(s)}{\Theta_{e}^{*}(s)}=\frac{k_{p} V_{m} s+k_{i} V_{m}}{s^{2}+k_{p} V_{m} s+k_{i} V_{m}}=\frac{2 \zeta \omega_{n} s+\omega_{n}^{2}}{s^{2}+2 \zeta \omega_{n} s+\omega_{n}^{2}}
$$

where $\zeta$ is called the damping ratio and $\omega_{n}$ is called the undamped natural frequency of the system. From (22), we have

$$
k_{i}=\frac{\omega_{n}^{2}}{V_{m}}
$$

and

$$
k_{p}=\frac{2 \zeta \omega_{n}}{V_{m}}
$$

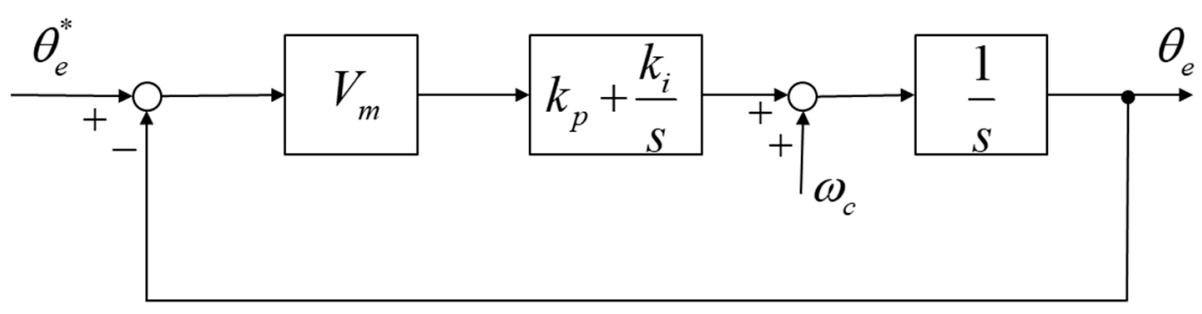

Figure 7. The transfer function block diagram of the PLL.

Thus, by giving the parameters value of $\zeta, \omega_{n}$, and $V_{m}$, which can be the generator line-to-line rating voltage, the parameters of PI controller in the phase-locked loop can be obtained by (23) and (24).

After the line voltage phase angle is locked, the phase angle of the phase voltage $v_{a n}$ is obtained as

$$
\theta_{a n}=\theta_{e}-\frac{\pi}{6}
$$


The three-phase phase voltage of the wind generator then can be reconstructed by

$$
\left[\begin{array}{c}
v_{a n} \\
v_{b n} \\
v_{c n}
\end{array}\right]=\frac{V_{m}}{\sqrt{3}}\left[\begin{array}{c}
\cos \theta_{a n} \\
\cos \left(\theta_{a n}-\frac{2 \pi}{3}\right) \\
\cos \left(\theta_{a n}+\frac{2 \pi}{3}\right)
\end{array}\right]
$$

where the voltage magnitude $V_{m}$ can be obtained from the $v_{d}$ component of the proposed phase-locked loop in Figure 6. However, the output line-to-line voltages of the wind generator are PWM switching signals which have to be filtered by a low-pass filter (LPF) to get the three-phase line-to-line fundamental signals before going to the PLL block. The LPF will produce magnitude reduction and phase lag of the input signal, which should be compensated. For a first-order LPF with the following transfer function,

$$
T(s)=\frac{\omega_{b}}{s+\omega_{b}}
$$

where $\omega_{b}$ is the bandwidth of the LPF. The magnitude reduction and phase lag of the transfer function is, respectively, as

$$
|T(j \omega)|=\frac{\omega_{b}}{\sqrt{\omega_{e}^{2}+\omega_{b}^{2}}}
$$

and

$$
\angle \phi_{L P F}=\tan ^{-1} \frac{\omega_{e}}{\omega_{b}}
$$

Therefore, the three-phase phase voltage of the wind generator in (26) should be modified as

$$
\left[\begin{array}{c}
v_{a n} \\
v_{b n} \\
v_{c n}
\end{array}\right]=\frac{\sqrt{\omega_{e}^{2}+\omega_{b}^{2}}}{\omega_{b}} \frac{V_{m}}{\sqrt{3}}\left[\begin{array}{c}
\cos \left(\theta_{a n}+\phi_{L P F}\right) \\
\cos \left(\theta_{a n}+\phi_{L P F}-\frac{2 \pi}{3}\right) \\
\cos \left(\theta_{a n}+\phi_{L P F}+\frac{2 \pi}{3}\right)
\end{array}\right]
$$

Figure 8 shows the proposed PLL scheme and the reconstruction of the three phase voltages with the magnitude reduction and phase lag compensation due to the LPF effect in PSIM. The simulation verification is shown in Figure 9. As can be seen, given a $60 \mathrm{~Hz}, 110 \mathrm{~V}$ rms three-phase line voltage, the reconstructed phase voltage $v_{a n}$ has 30 degrees of phase lag and $1 / \sqrt{3}$ magnitude ratio as compared to the line voltage $v_{a b}$. Furthermore, $v_{q}$ is approaching zero and $v_{d}$ is approaching a constant voltage equal to $V_{m}$. 


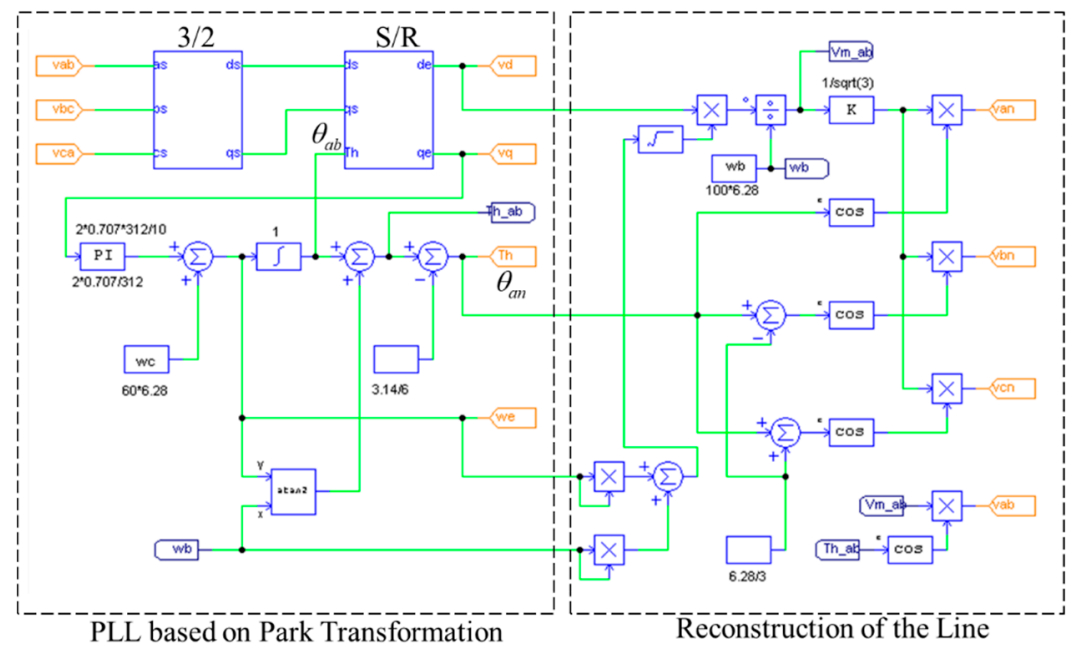
and Phase Voltages

Figure 8. PLL scheme with the line and phase voltages reconstruction in PSIM.

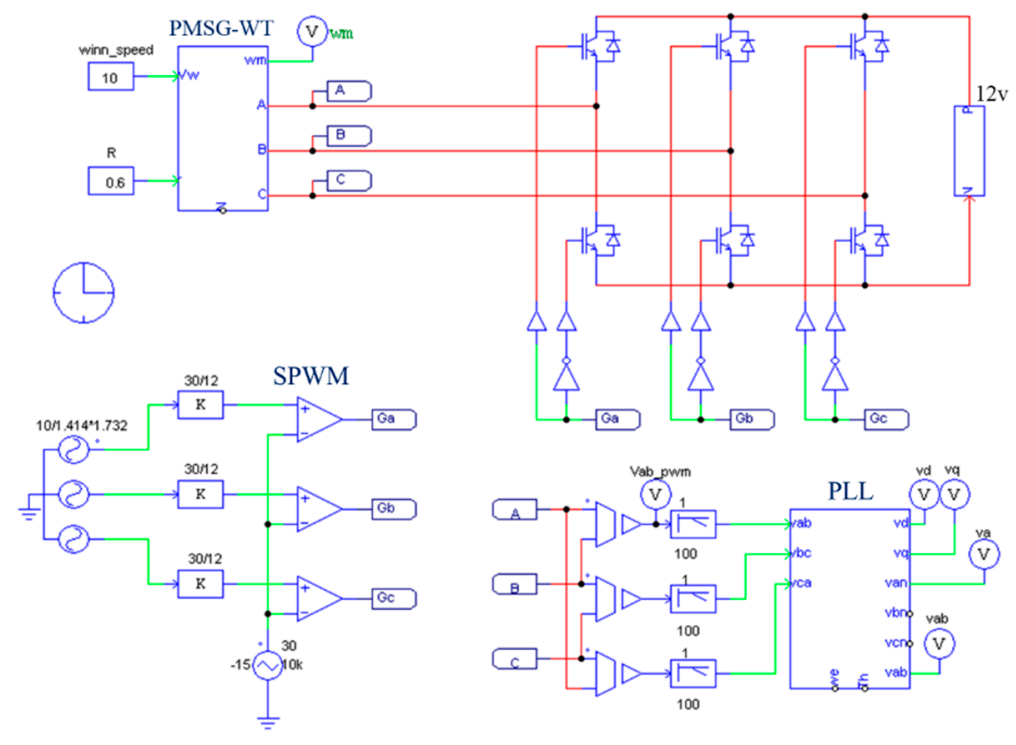

(a)
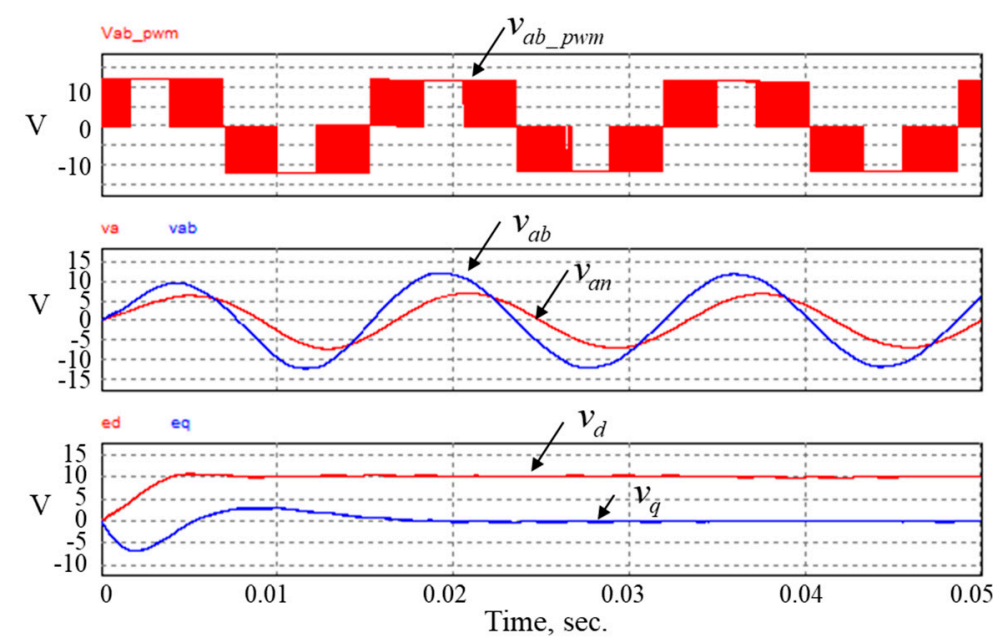

(b)

Figure 9. (a) The PLL scheme simulation test in the PWM control of the wind generator; (b) Simulation waveforms. 


\subsection{Current Control with Power Factor Correction}

The current vector control method proposed in this paper for unity power factor correction to control the three-phase phase currents in phase with the three-phase phase voltages is voltage phase-oriented with the three-phase voltage vector aligned on the $d$-axis. To do this, the phase angle of phase voltage extracted from the PLL scheme described above is used for the coordinate transformation between the stationary $\alpha-\beta$ frame and the synchronous $d-q$ frame. A PI current controller is designed in the $d-q$ axis, respectively. The current references for the $d-q$ components are as follows:

$$
\left[\begin{array}{l}
i_{d}^{*} \\
i_{q}^{*}
\end{array}\right]=\left[\begin{array}{c}
I_{m} \\
0
\end{array}\right]
$$

where $I_{m}$ can be given by the outer-loop power signal feedback (PSF) MPPT control $[7,8]$. Under this control method, the three-phase currents can be controlled as

$$
\left[\begin{array}{c}
i_{a} \\
i_{b} \\
i_{c}
\end{array}\right]=\left[\begin{array}{c}
I_{m} \cos \theta_{a n} \\
I_{m} \cos \left(\theta_{a n}-\frac{2 \pi}{3}\right) \\
I_{m} \cos \left(\theta_{a n}+\frac{2 \pi}{3}\right)
\end{array}\right]
$$

in which the argument $\theta_{a n}$ has been compensated by adding the term in (29) due to the LPF. The modelling and design of the PI current controller is described as follows.

With the three-phase voltage vector aligned on the $d$-axis, the three-phase stator voltage equation in the $d-q$ frame can be derived by substituting the three-phase stator voltage Equation (4) in Section 2 into (33) and (34) as follows.

$$
\begin{gathered}
{\left[\begin{array}{c}
e_{\alpha} \\
e_{\beta}
\end{array}\right]=\left[\begin{array}{ccc}
1 & 0 & 0 \\
0 & \frac{1}{\sqrt{3}} & \frac{-1}{\sqrt{3}}
\end{array}\right]\left[\begin{array}{c}
v_{a} \\
v_{b} \\
v_{c}
\end{array}\right]} \\
{\left[\begin{array}{c}
e_{d} \\
e_{q}
\end{array}\right]=\left[\begin{array}{cc}
\cos \theta_{a n} & \sin \theta_{a n} \\
-\sin \theta_{a n} & \cos \theta_{a n}
\end{array}\right]\left[\begin{array}{c}
e_{\alpha} \\
e_{\beta}
\end{array}\right]} \\
{\left[\begin{array}{c}
e_{d} \\
e_{q}
\end{array}\right]=\omega_{r} \psi_{r}\left[\begin{array}{c}
\sin \left(\theta_{a n}-\theta_{r}\right) \\
\cos \left(\theta_{a n}-\theta_{r}\right)
\end{array}\right]-L_{s}\left[\begin{array}{c}
\frac{d i_{d}}{d t} \\
\frac{d t_{q}}{d t}
\end{array}\right]+L_{s} \omega_{r}\left[\begin{array}{c}
i_{q} \\
-i_{d}
\end{array}\right]-R_{s}\left[\begin{array}{c}
i_{d} \\
i_{q}
\end{array}\right]}
\end{gathered}
$$

where $e_{d}$ and $e_{q}$ are the stator voltage components in the second $d-q$ frame $\left(d_{2}-q_{2}\right)$, which has a phase lag compared to the PLL $d-q$ frame $\left(d_{1}-q_{1}\right)$, as shown in Figure 10. Then, the state equation can be obtained from (35) as

$$
\left[\begin{array}{c}
\frac{d i_{d}}{d t} \\
\frac{d i_{q}}{d t}
\end{array}\right]=\frac{\omega_{r} \psi_{r}}{L_{s}}\left[\begin{array}{c}
\sin \left(\theta_{a n}-\theta_{r}\right) \\
\cos \left(\theta_{a n}-\theta_{r}\right)
\end{array}\right]+\omega_{r}\left[\begin{array}{c}
i_{q} \\
-i_{d}
\end{array}\right]-\frac{R_{s}}{L_{s}}\left[\begin{array}{c}
i_{d} \\
i_{q}
\end{array}\right]-\frac{1}{L_{s}}\left[\begin{array}{c}
e_{d} \\
e_{q}
\end{array}\right]
$$




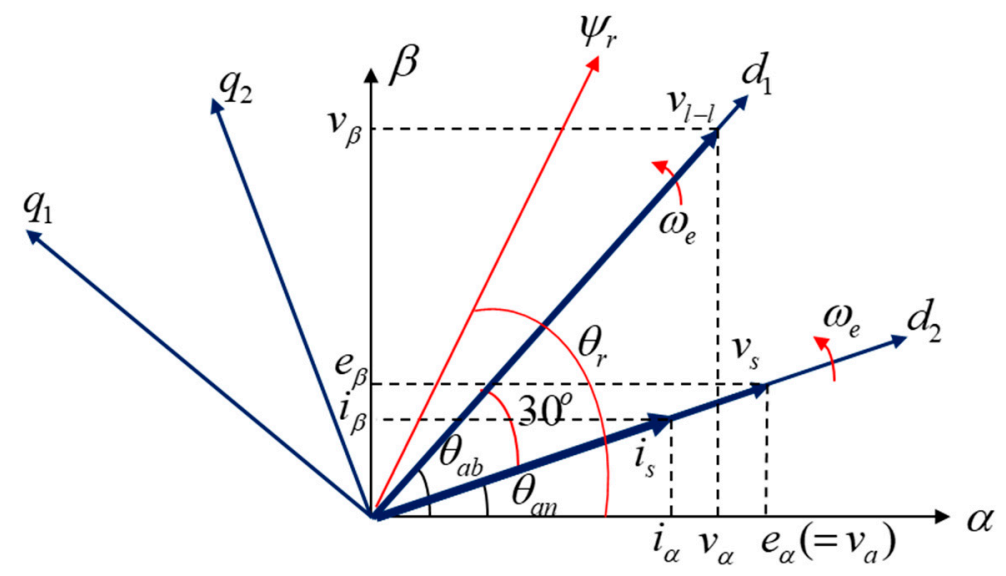

Figure 10. The geometric relationship of the two $d-q$ frames.

Figure 11 shows the controlled plant and the controller block diagram in the $d$-axis and $q$-axis, respectively. As can be seen, the PI controller is followed by a decoupling compensation for eliminating the coupling effect of $i_{q}$ to $i_{d}$ on the $d$-axis plant and $i_{d}$ to $i_{q}$ on the $q$-axis plant, respectively. The term $\omega_{r} \psi_{r} \sin \left(\theta_{a n}-\theta_{r}\right)$ on the d-axis plant and $\omega_{r} \psi_{r} \cos \left(\theta_{a n}-\theta_{r}\right)$ on the q-axis plant can be seen as a disturbance for the controlled current components $i_{d}$ and $i_{q}$, respectively, which can be regulated by the PI controllers.

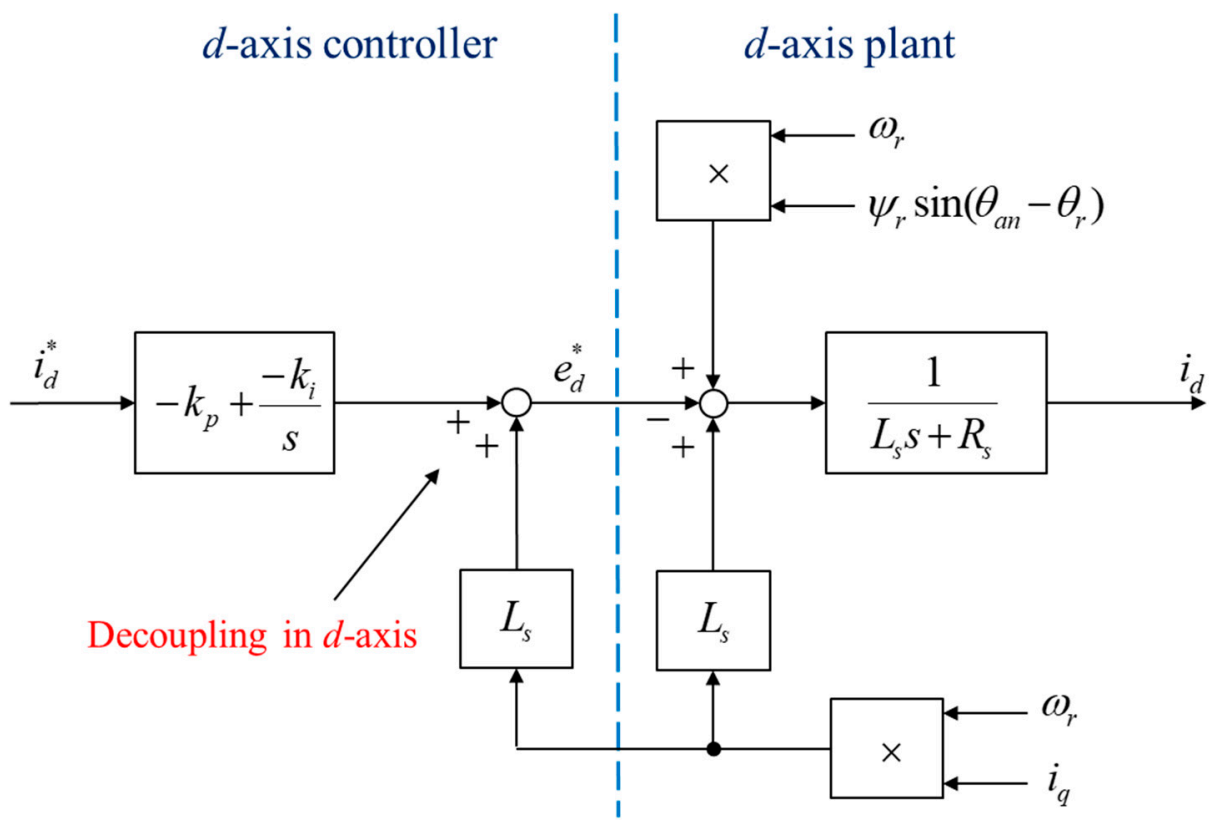

(a)

Figure 11. Cont. 


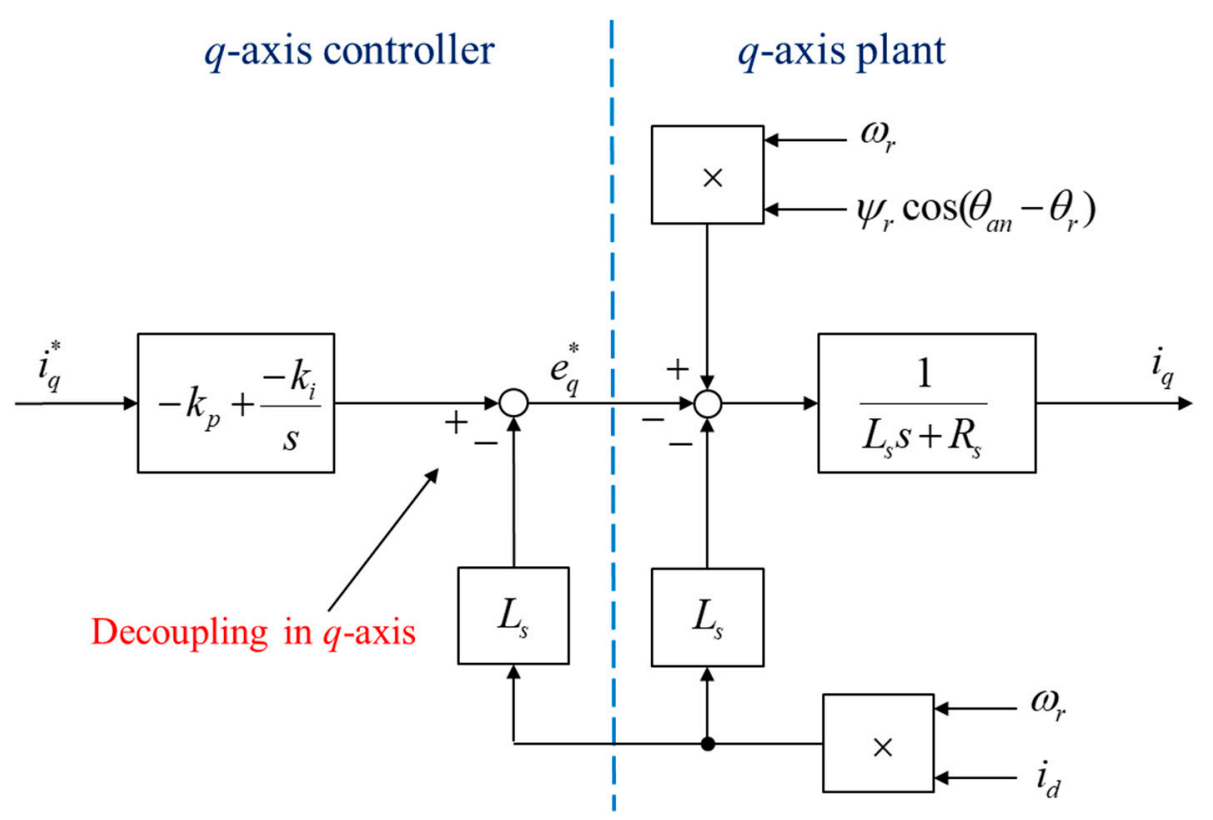

(b)

Figure 11. Transfer function block diagram of current decoupling control: (a) $d$-axis; (b) $q$-axis.

By using the pole-zero cancellation method with the decoupling control in the $d$-axis and $q$-axis, respectively, the closed-loop transfer function for the both axes are the same and can be written as a first-ordered system by

$$
G_{c l}(s)=\frac{\frac{k_{i}}{R_{s}}}{s+\frac{k_{i}}{R_{s}}}=\frac{K}{s+K}
$$

where $K$ is the bandwidth of the system with

$$
K=\frac{k_{i}}{R_{S}}
$$

Thus, by setting the bandwidth of the closed-loop current control system to be $300 \mathrm{~Hz}$, the PI controller parameters can be obtained.

\section{Simulation and Experimental Verifications}

The simulation verification of the phase-voltage oriented vector control of a wind generator for the unity power factor correction in PSIM is shown in Figure 12a. Given the wind speed of $10 \mathrm{~m} / \mathrm{s}$ and the current reference $I_{m}=6 \mathrm{~A}$ after the time of $0.1 \mathrm{~s}$, the simulation result is shown in Figure $12 \mathrm{~b}$. As can be seen, $i_{q}$ is approaching zero because the zero current reference is given on the $q$-axis and $i_{d}$ is rising quickly to a constant value equal to $I_{m}$. Furthermore, the phase current $i_{a}$ is in phase with the phase voltage $v_{a n}$. The reconstruction of three phase line voltages $v_{a b}, v_{b c}, v_{c a}$, the generator rotation speed $\omega_{m}$, and the theta angle $\theta_{a n}$ from the PLL block are also shown in the figure. It can be seen that the generator rotating speed is increased linearly due to no load before the time of $0.1 \mathrm{~s}$. The generator rotating speed is increased with slower slope because the generator load torque is produced when the current reference of $6 \mathrm{~A}$ is given. 


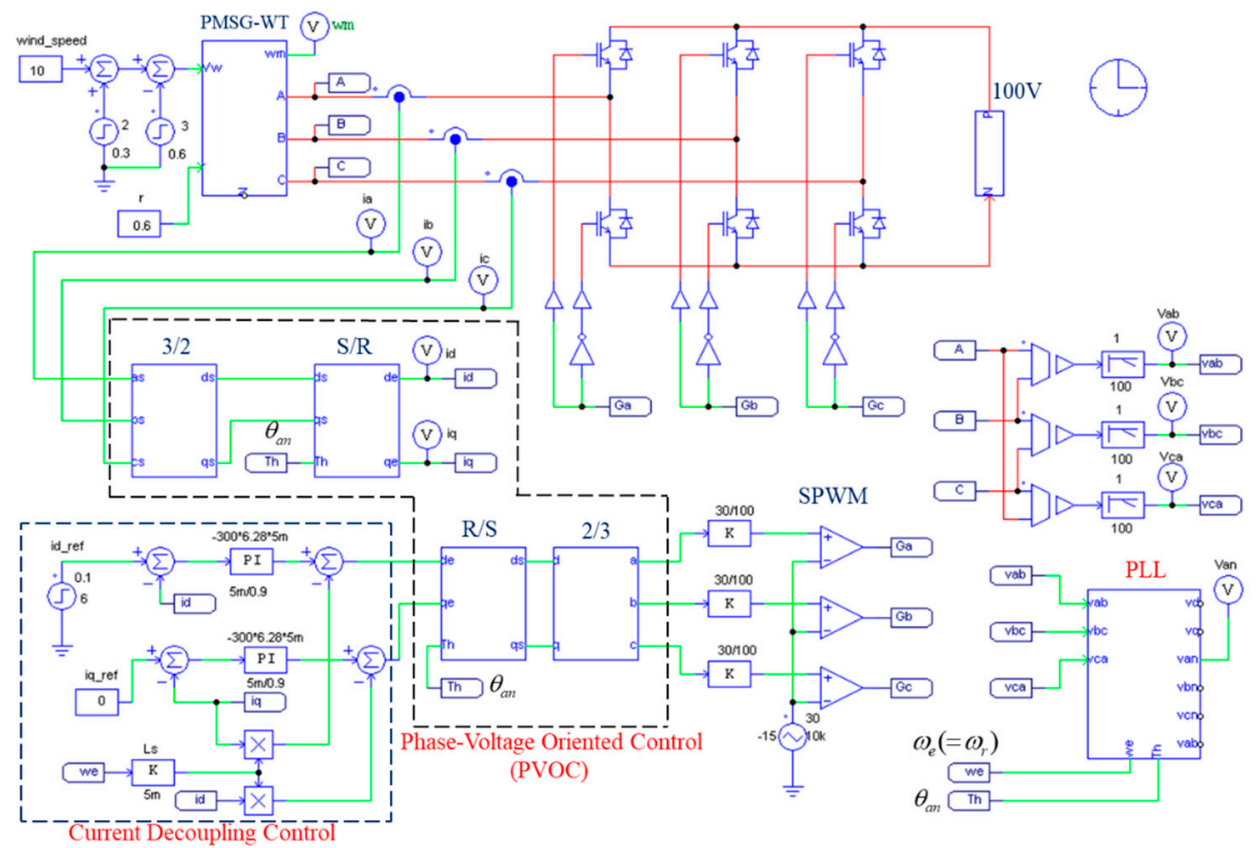

(a)

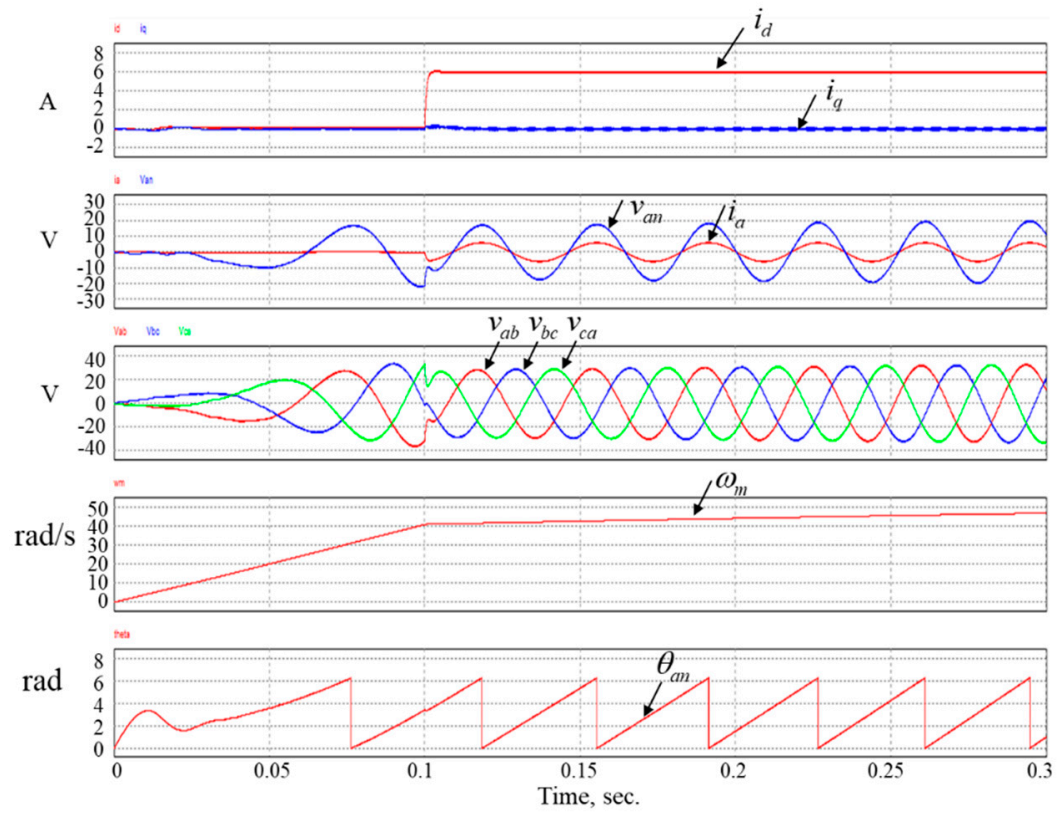

(b)

Figure 12. (a) Simulation verification for the PFC control in PSIM; (b) Simulation waveforms for the fixed wind speed at $10 \mathrm{~m} / \mathrm{s}$.

Figure 13 shows the simulation waveforms for the wind speed variations with sudden change from $10 \mathrm{~m} / \mathrm{s}$ to $12 \mathrm{~m} / \mathrm{s}$ at $0.3 \mathrm{~s}$. and down to $9 \mathrm{~m} / \mathrm{s}$ at $0.6 \mathrm{~s}$. As can be seen, $i_{d}$ remains at the constant value of $6 \mathrm{~A}$ and $i_{q}$ remains at zero. The phase current $i_{a}$ is in phase with the phase voltage $v_{a n}$ even though the phase voltage increases from $0.3 \mathrm{~s}$ to $0.6 \mathrm{~s}$, and then decreases from $0.6 \mathrm{~s}$ to $0.9 \mathrm{~s}$ due to the wind speed variations. The generator rotating speed is also increasing and then decreasing corresponding to the wind speed sudden variations. The simulation waveforms in Figures 12 and 13 indicate the correct operation of the proposed PLL and PFC control scheme. 


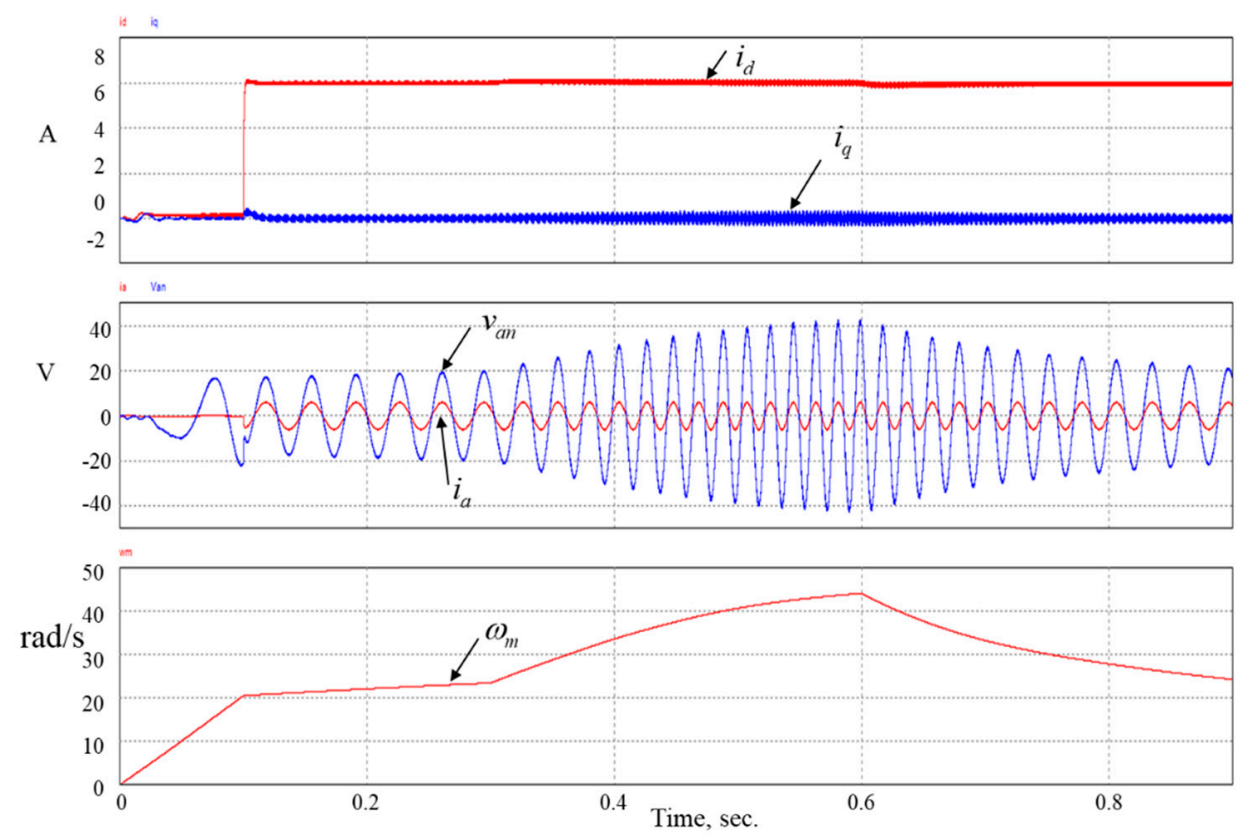

Figure 13. Simulation waveforms for the wind speed variations from $10 \mathrm{~m} / \mathrm{s}$ to $12 \mathrm{~m} / \mathrm{s}$ at $0.3 \mathrm{~s}$. and down to $9 \mathrm{~m} / \mathrm{s}$ at $0.6 \mathrm{~s}$.

The developed method is compared with an existing PFC control of a directly driven PM wind generator which is based on RFOC control by calculating the stator current using the generator parameters [20]. In the conventional RFOC current control method, the phase angle for the Park and inverse-Park coordinate transformation is the rotor flux angle with the magnet rotor flux vector oriented as $d$-axis. The stator voltage equation in the $d$ - $q$ frame can be derived by setting $\theta_{a n}=\theta_{r}$ in (35) as follows.

$$
\left[\begin{array}{l}
e_{d} \\
e_{q}
\end{array}\right]=\left[\begin{array}{c}
0 \\
\omega_{r} \psi_{r}
\end{array}\right]-L_{s}\left[\begin{array}{c}
\frac{d i_{d}}{d t} \\
\frac{d i_{q}}{d t}
\end{array}\right]+L_{s} \omega_{r}\left[\begin{array}{c}
i_{q} \\
-i_{d}
\end{array}\right]-R_{s}\left[\begin{array}{c}
i_{d} \\
i_{q}
\end{array}\right]
$$

If not using PFC control, the current reference is given on the $q$-axis with $i_{d}=0$, and the simulation result is shown in Figure 14 . As can be seen, $i_{d}$ is approaching zero and $i_{q}$ is rising quickly to a constant value equal to $I_{m}(6 \mathrm{~A})$. However, the phase current and the phase voltage are out of phase with phase current leading the phase voltage. 


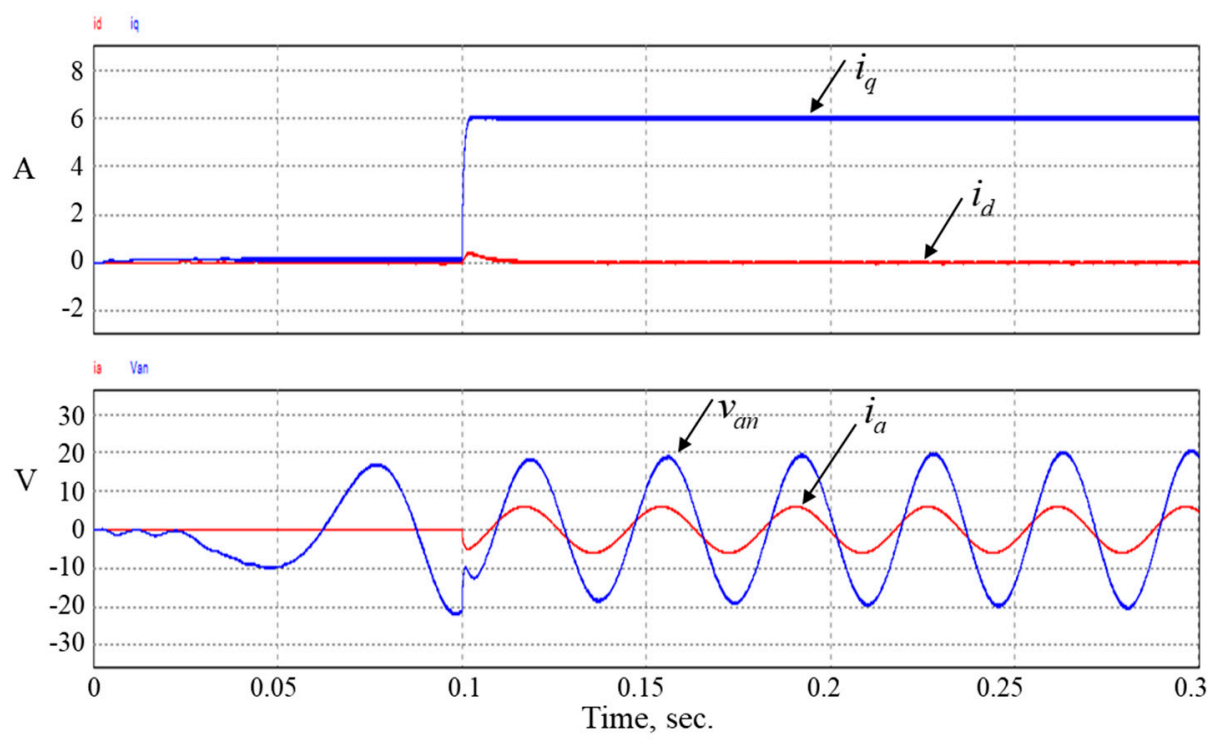

Figure 14. Simulation waveforms with conventional RFOC control without PFC.

For unit power factor control, the existing method with RFOC presented in [20] is on the basis of the following condition:

$$
\frac{i_{d}}{i_{q}}=\frac{e_{d}}{e_{q}}
$$

In the steady-state operation, the directive terms in (39) can be neglected, so it can be rewritten as

$$
\left[\begin{array}{c}
e_{d} \\
e_{q}
\end{array}\right]=\left[\begin{array}{c}
0 \\
\omega_{r} \psi_{r}
\end{array}\right]+L_{s} \omega_{r}\left[\begin{array}{c}
i_{q} \\
-i_{d}
\end{array}\right]-R_{s}\left[\begin{array}{c}
i_{d} \\
i_{q}
\end{array}\right]
$$

Substituting (41) into (40) yields

$$
L_{s} i_{d}^{2}-\psi_{r} i_{d}+L_{s} i_{q}^{2}=0
$$

The above equation can be solved approximately as

$$
\left[\begin{array}{c}
i_{d} \\
i_{q}
\end{array}\right]=\left[\frac{\frac{\psi_{r}-\sqrt{\psi_{r}^{2}-4 L_{s}^{2} i_{q}^{2}}}{2 L_{s}}}{\sqrt{I_{m}^{2}-i_{d}^{2}}}\right] \approx\left[\begin{array}{c}
\frac{\psi_{r}-\sqrt{\psi_{r}^{2}-4 L_{S}^{2} 2_{m}^{2}}}{2 L_{s}} \\
\sqrt{I_{m}^{2}-i_{d}^{2}}
\end{array}\right]
$$

because $4 L_{s}^{2} i_{q}^{2}<<\psi_{r}^{2}$, and hence $i_{q} \approx I_{m}$.

Figure 15 shows the simulation result of the existing PFC control with RFOC method given the current control reference according to (43) and wind speed of $10 \mathrm{~m} / \mathrm{s}$. As can be seen, the phase current looks in phase with phase voltage. Actually, with the approximation in (43),

$$
\frac{i_{d}}{i_{q}}>\frac{e_{d}}{e_{q}}
$$



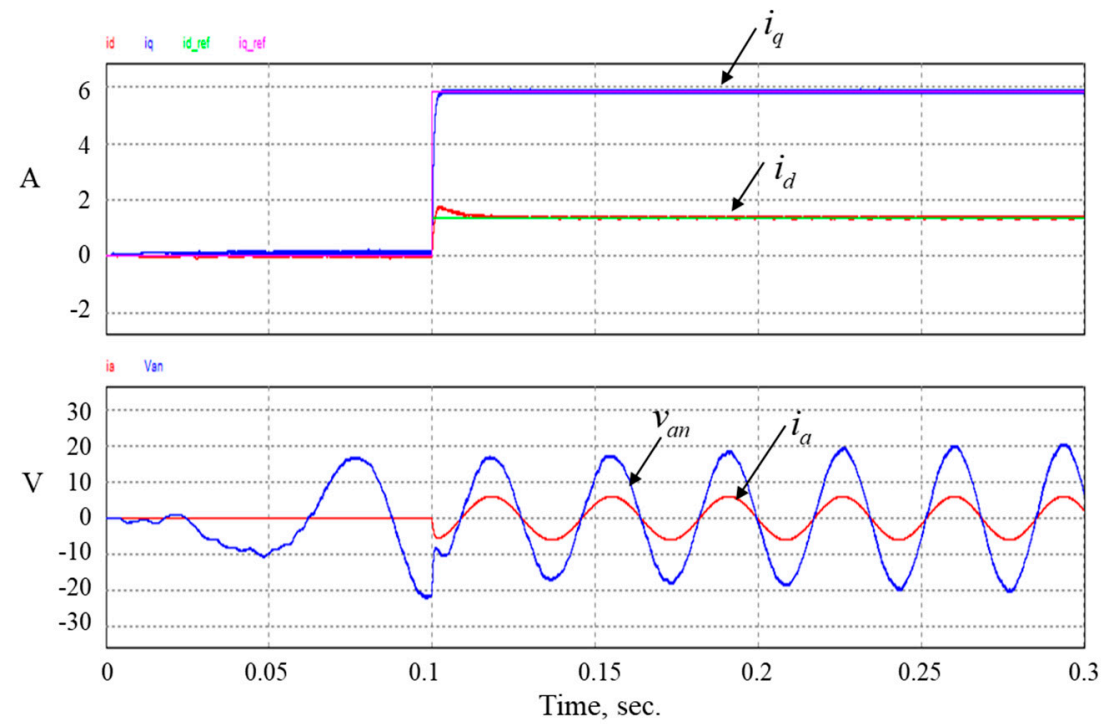

Figure 15. Simulation waveforms for the existing PFC with RFOC control.

Thus, there is little phase difference between the phase current and the phase voltage due to the approximation. The comparison of the above three current control methods is summarized in Table 2. As can be seen, the proposed PFC current control method based on PVOC has better power factor than other two control methods based on RFOC and has no requirement of the rotor position sensor or sensorless estimator.

Table 2. Comparison of the three current control method.

\begin{tabular}{|c|c|c|c|}
\hline Control Method & $\begin{array}{l}\text { PFC Current Control } \\
\text { Based on PVOC }\end{array}$ & $\begin{array}{l}\text { Current Control Based } \\
\text { on RFOC (without PFC) }\end{array}$ & $\begin{array}{l}\text { PFC Current Control } \\
\text { Based on RFOC }\end{array}$ \\
\hline Current Reference & $\begin{array}{l}i_{d}^{*}=I_{m} \\
i_{q}^{*}=0\end{array}$ & $\begin{array}{l}i_{d}^{*}=0 \\
i_{q}^{*}=I_{m}\end{array}$ & $\begin{array}{l}i_{d}^{*}=0 \\
i_{q}^{*}=I_{m}\end{array}$ \\
\hline $\begin{array}{c}\text { Phase Angle for the Park } \\
\text { and Inverse-Park } \\
\text { Transformation }\end{array}$ & $\theta_{a n}$ & $\theta_{r}$ & $\theta_{r}$ \\
\hline Power Factor & $\mathrm{PF}=1$ & $\mathrm{PF}<1$ & $\mathrm{PF} \approx 1$ \\
\hline $\begin{array}{l}\text { Rotor Position Sensor or } \\
\text { Sensorless Estimator }\end{array}$ & Non-Required & Required & Required \\
\hline
\end{tabular}

Figure 16 shows the experimental platform for the verification of the proposed PVOC control of a wind generator for unity power factor correction. The wind is generated by an inverter driven blower which can produce variable wind speed. A vertical axis wind turbine charger, which consists of a 400-W wind turbine, a PWM controlled rectifier, a 12-V battery, and a TI TMS320F28335 DSP chip, has been employed to verify the proposed control method. 


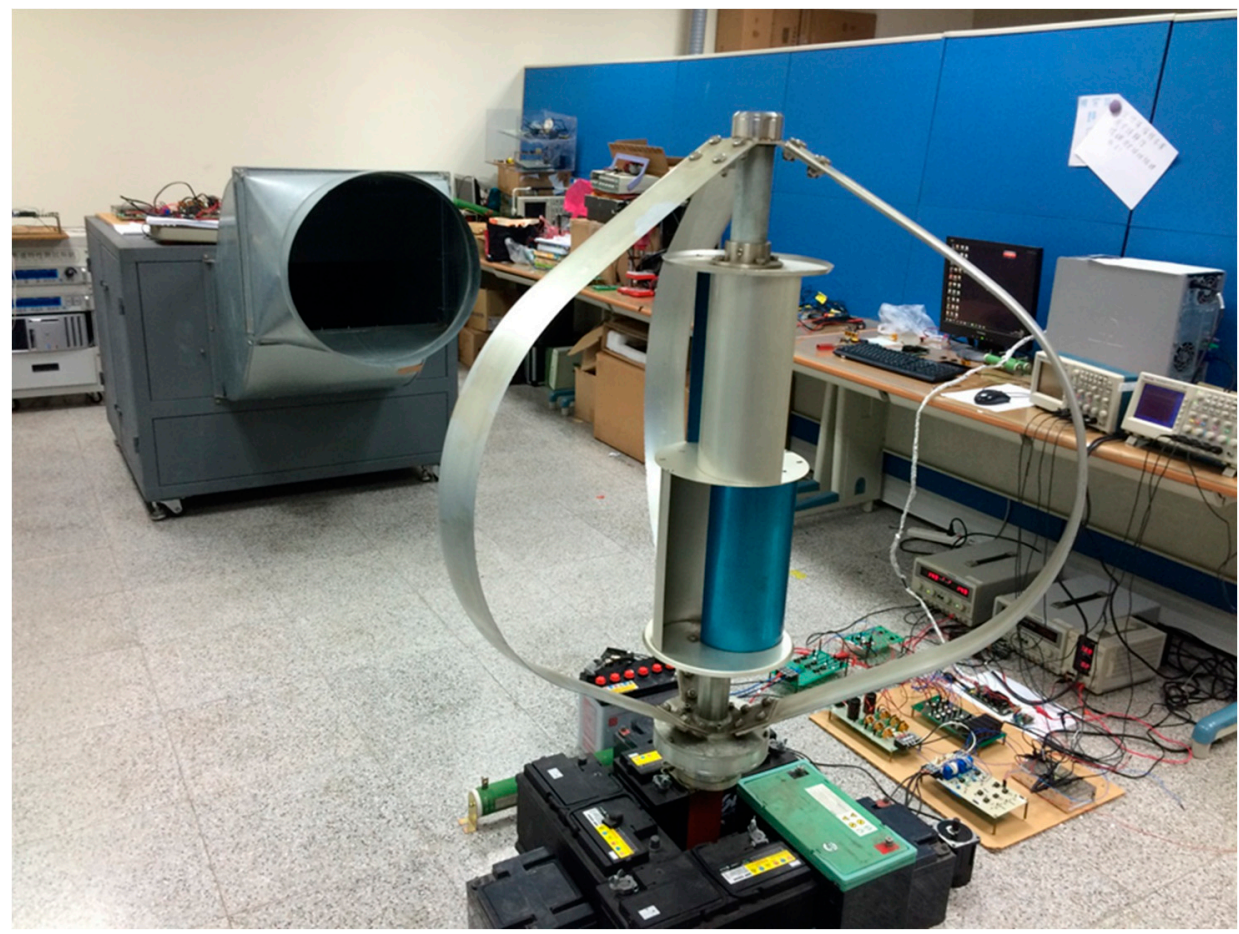

Figure 16. The experiment platform of the PMSG wind generator.

Figure 17 shows experimental waveforms for the PLL scheme. As can be seen from Figure 17a that after the phase is locked, the $q$-component of the line voltage, $v_{q}$, is equal to zero and the $d$-component, $v_{d}$, is kept to be near a constant which is the amplitude $V_{m}$ of the line voltage. The waveforms of the phase voltage argument, $\theta_{a n}$, together with the reconstruction of the phase voltage $v_{a n}$ and the line voltage $v_{a b}$ from the PLL block are shown in Figure $17 \mathrm{~b}$. As can be seen, the phase voltage $v_{a n}$ has a phase lag of 30 degrees and about $1 / \sqrt{3}$ of amplitude compared to the line voltage $v_{a b}$.

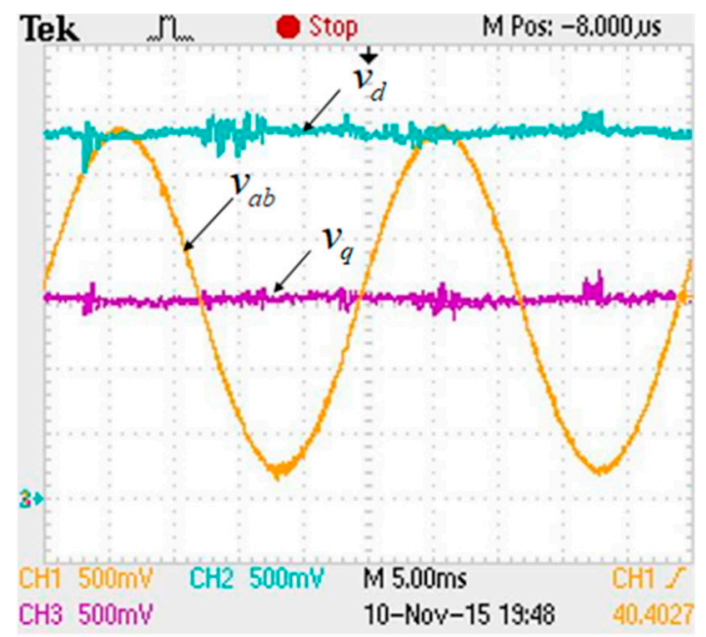

(a)

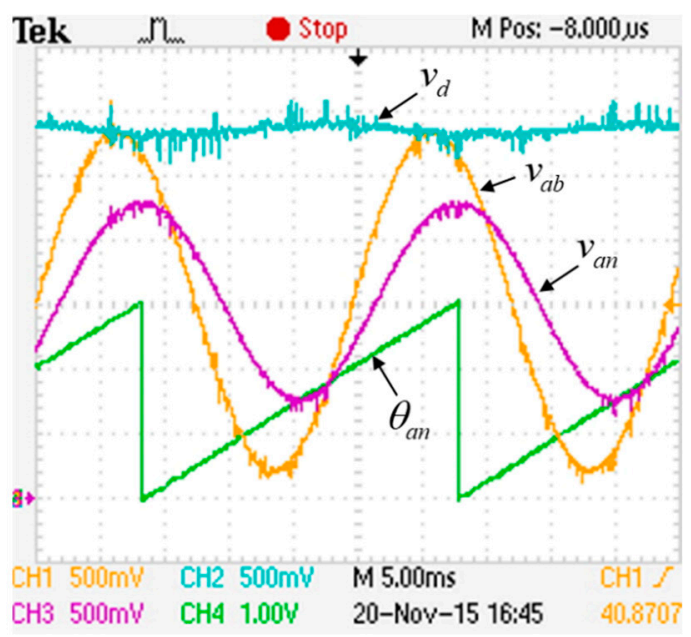

(b)

Figure 17. The PLL experimental results (4.55 V/div for voltage, $1.90 \mathrm{rad} / \mathrm{div}$ for argument angle): (a) line voltage $v_{a b}$ and $d$ - $q$ components; (b) phase voltage argument, phase voltage, and line voltage waveforms.

Figure 18 shows the comparison of experimental results with and without using PVOC control. As can be seen from Figure 18a that the phase currents lead the phase voltages in the open-loop PWM control test. But, as can be seen from Figure 18b, the phase currents are almost in phase with the phase voltages with the proposed closed-loop PVOC control method. 


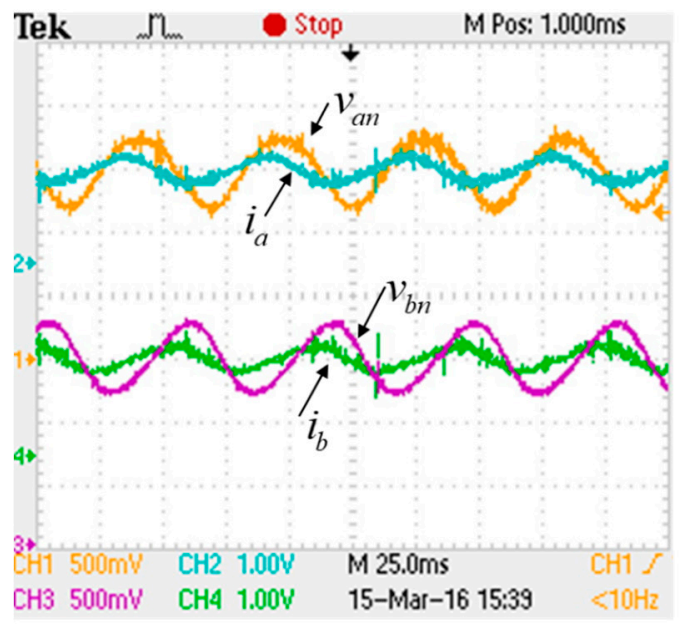

(a)

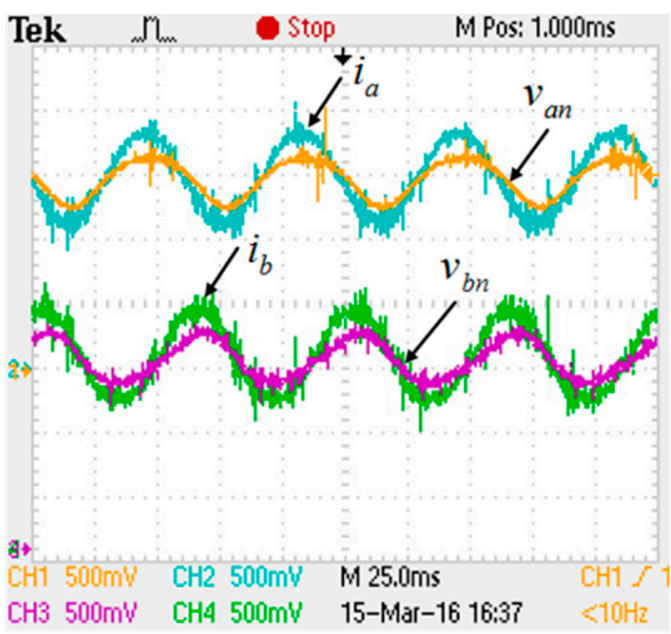

(b)

Figure 18. The control experimental results: (a) Open-loop PWM control (4.55 V/div for voltage, 9.09 $\mathrm{A} /$ div for current); (b) Closed-loop current control (4.55 V/div for voltage, $4.55 \mathrm{~A} /$ div for current).

\section{Conclusions}

In this work, the design and implementation of a phase-voltage oriented control (PVOC) of a PMSG wind generator for unity power factor correction has been done. The proposed control method is different from the conventional rotor flux-oriented control (RFOC) method which might need rotor position sensor or sensorless estimator. The modeling of the PMSG wind generator in the three-phase $a-b-c$ stationary frame which is a combination of circuit and equation-based model has been firstly constructed in PSIM for simulation analysis. The proposed control system is operated in two separately rotating $d-q$ frames. One is for a phase-locked loop (PLL) and the other one is for the PVOC current control loop. A PI controller functioned as a low pass filter in the PLL loop is designed for extracting the phase-voltage angle for the coordinate transformation between the stationary $\alpha-\beta$ frame and the synchronously rotating $d-q$ frame in the current PVOC control loop. The $d-q$ modeling of the PMSG with the three-phase voltage vector aligned on the $d$-axis has been then derived and based on which an another PI controller followed by decoupling control has been designed, so that the three-phase currents are in phase with the three-phase output voltages of the wind generator for unity power factor correction by setting the current reference on the $d$-axis, which can be given by the outermost power signal feedback (PSF) MPPT control loop. The simulation results by using PSIM tool under variable wind speed conditions show the performance of the proposed PFC current control method. The conventional current control based on RFOC without using PFC and an existing PFC current control method based on RFOC are also illustrated and summarized for the comparisons with the proposed PFC current control method based on PVOC. The comparison summary shows that the proposed method has better power factor than the other two methods based on RFOC. The other advantage of the proposed control method is without using the rotor position sensor, and hence improving the reliability. The controller design is experimentally verified by using a TI TMS320F28335 digital control chip. The PSF MPPT control in the outer loop tracking the maximum power curve will be done in the near future.

Author Contributions: Conceptualization, M.-F.T.; Data curation, M.-F.T.; Formal analysis, M.-F.T.; Funding acquisition, M.-F.T.; Investigation, M.-F.T.; Methodology, M.-F.T.; Project administration, C.-S.T.; Resources, M.-F.T. and B.-Y.L.; Software, B.-Y.L.; Supervision, C.-S.T.; Validation, C.-S.T.; Visualization, M.-F.T. and C.-S.T.; Writing—original draft, M.-F.T. and C.-S.T.; Writing—review \& editing, M.-F.T. All authors have read and agreed to the published version of the manuscript.

Funding: This research was funded by Project number: MUST-109-mission-2, from Ministry of Education (MOE), Taiwan.

Conflicts of Interest: The authors declare no conflict of interest. 


\section{Nomenclature}

\begin{tabular}{|c|c|}
\hline$R_{s}$ & Stator resistance per phase. \\
\hline$L_{s}$ & Stator inductance per phase. \\
\hline$L_{l s}$ & Stator leakage inductance per phase. \\
\hline$L_{m}$ & Magnetizing inductance per phase. \\
\hline$L_{a b}, L_{b c}, L_{c a}$ & Mutual inductances. \\
\hline$v_{a}, v_{b}, v_{c}$ & Stator phase voltages in $a-b-c$ axes. \\
\hline$v_{a b}, v_{b c}, v_{c a}$ & Stator line voltages in $a-b-c$ axes. \\
\hline$e_{a}, e_{b}, e_{c}$ & Stator electromotive forces in $a-b-c$ axes. \\
\hline$i_{a}, i_{b}, i_{c}$ & Stator phase currents in $a-b-c$ axes. \\
\hline$\psi_{a}, \psi_{b}, \psi_{c}$ & Stator flux linkages in $a-b-c$ axes. \\
\hline$v_{a n}, v_{b n}, v_{c n}$ & Reconstruction of stator phase voltages in $a-b-c$ axes. \\
\hline$\psi_{r}$ & Rotor flux linkage. \\
\hline$\theta_{r}$ & Rotor electrical angle. \\
\hline$\theta_{r 0}$ & Rotor initial electrical angle. \\
\hline$\omega_{r}$ & Rotor electrical speed. \\
\hline$\omega_{m}$ & Generator mechanical speed. \\
\hline$P$ & Rotor magnet pole number. \\
\hline$T_{e}$ & Generator torque. \\
\hline$T_{m}$ & Wind turbine mechanical torque. \\
\hline$J$ & moment inertia of wind generator. \\
\hline$B$ & viscous coefficient of the wind generator. \\
\hline$P_{w t}$ & Wind turbine power. \\
\hline$r$ & Wind turbine blade length (rotation radius). \\
\hline$v_{w}$ & Wind speed. \\
\hline$\lambda$ & Wind turbine tip speed ratio (TSR). \\
\hline$C_{p}$ & Wind turbine power efficiency. \\
\hline$V_{m}$ & Stator line voltage amplitude. \\
\hline$\omega_{e}$ & Stator angular frequency. \\
\hline$\theta_{e}$ & Synchronous rotating angle of $d_{1}-q_{1}$ frame for PLL. \\
\hline$\theta_{a b}$ & Line voltage $v_{a b}$ argument. \\
\hline$\theta_{a n}$ & Phase voltage $v_{a n}$ argument. \\
\hline$v_{\alpha}, v_{\beta}$ & Stator line voltages in $\alpha$ - $\beta$ axes. \\
\hline$v_{d}, v_{q}$ & Stator line voltages in $d_{1}-q_{1}$ axes. \\
\hline$e_{\alpha}, e_{\beta}$ & Stator phase voltages in $\alpha-\beta$ axes. \\
\hline$e_{d}, e_{q}$ & Stator phase voltages in $d_{2}-q_{2}$ axes. \\
\hline$i_{d}, i_{q}$ & Stator phase currents in $d_{2}-q_{2}$ axes. \\
\hline$I_{m}$ & Current control reference amplitude. \\
\hline$\zeta$ & Damping ratio of a second order system \\
\hline$\omega_{n}$ & Undamped natural frequency of a second order system. \\
\hline$\omega_{b}$ & Bandwidth of a low-pass filter. \\
\hline$\omega_{c}$ & Center frequency of VCO. \\
\hline
\end{tabular}

\section{References}

1. Song, D.; Yang, J.; Su, M.; Liu, A.; Liu, Y.; Joo, Y.H. A Comparison Study between Two MPPT Control Methods for a Large Variable-Speed Wind Turbine under Different Wind Speed Characteristics. Energies 2017, 10, 613. [CrossRef]

2. Cheng, Q.; Liu, X.; Ji, H.; Kim, K.C.; Yang, B. Aerodynamic Analysis of a Helical Vertical Axis Wind Turbine. Energies 2017, 10, 575. [CrossRef]

3. Luo, Z.; Sun, Z.; Ma, F.; Qin, Y.; Ma, S. Power Optimization for Wind Turbines Based on Stacking Model and Pitch Angle Adjustment. Energies 2020, 13, 4158. [CrossRef]

4. Li, H.; Shi, K.L.; McLaren, P.G. Neural-Network-Based Sensorless Maximum Wind Energy Capture with Compensated Power Coefficient. IEEE Trans. Ind. Appl. 2005, 41, 1548-1556. [CrossRef] 
5. Chinchilla, M.; Arnaltes, S.; Burgos, J. Control of Permanent-Magnet Generators Applied to Variable-Speed Wind-Energy Systems Connected to the Grid. IEEE Trans. Energy Convers. 2006, 21, 130-135. [CrossRef]

6. Chedid, R.; Mrad, F.; Basma, M. Intelligent control of a class of wind energy conversion systems. IEEE Trans. Energy Convers. 1999, 14, 1597-1604. [CrossRef]

7. Tan, K.; Islam, S. Optimum Control Strategies in Energy Conversion of PMSG Wind Turbine System without Mechanical Sensors. IEEE Trans. Energy Convers. 2004, 19, 392-399. [CrossRef]

8. Simoes, M.; Bose, B.; Spiegel, R. Design and performance evaluation of a fuzzy-logic-based variable-speed wind generation system. IEEE Trans. Ind. Appl. 1997, 33, 956-965. [CrossRef]

9. Tanaka, T.; Toumiya, T.; Suzuki, T. Output control by hill-climbing method for a small scale wind power generating system. Renew. Energy 1997, 12, 387-400. [CrossRef]

10. Datta, R.; Ranganathan, V. A method of tracking the peak power points for a variable speed wind energy conversion system. IEEE Trans. Energy Convers. 2003, 18, 163-168. [CrossRef]

11. Wang, Q.; Chan, L. An independent maximum power extraction strategy for wind energy conversion systems. In Proceedings of the Engineering Solutions for the Next Millennium. 1999 IEEE Canadian Conference on Electrical and Computer Engineering, Edmonton, AB, Canada, 9-12 May 1999; pp. 1242-1249.

12. Koutroulis, E.; Kalaitzakis, K. Design of a maximum power tracking system for wind-energy-conversion applications. IEEE Trans. Ind. Electron. 2006, 53, 486-494. [CrossRef]

13. Lin, W.-M.; Hong, C.-M.; Cheng, F.-S. Fuzzy neural network output maximization control for sensorless wind energy conversion system. Energy 2010, 35, 592-601. [CrossRef]

14. Tsai, M.-F.; Tseng, C.-S.; Hung, Y.-H. A novel MPPT control design for wind-turbine generation systems using neural network compensator. In Proceedings of the 38th Annual Conference on IEEE Industrial Electronics Society, Montreal, QC, Canada, 25-28 October 2012; pp. 3521-3526.

15. Gamboa, G.; Elmes, J.; Hamilton, C.; Baker, J.; Pepper, M.; Batarseh, I. A unity power factor, maximum power point tracking battery charger for low power wind turbines. In Proceedings of the 25th Annual IEEE Applied Power Electronics Conference and Exposition (APEC), Palm Springs, CA, USA, 21-25 February 2010; pp. 143-148.

16. De Almeida, B.R.; Oliveira, D.S. Power converter for vertical wind energy conversion system. In Proceedings of the Brazilian Power Electronics Conference, Gramodo, Brazil, 27-31 October 2013; pp. 468-473.

17. Abdelrahem, M.; Hackl, C.M.; Kennel, R. Finite Position Set-Phase Locked Loop for Sensorless Control of Direct-Driven Permanent-Magnet Synchronous Generators. IEEE Trans. Power Electron. 2017, 33, 3097-3105. [CrossRef]

18. Islam, M.H.; Masud, M.R.; Razzak, M.A. Power Factor Correction for Wind Power Generation Systems using Modified Vienna Rectifier. In Proceedings of the Innovations in Power and Advanced Computing Technologies (i-PACT), Vellore, India, 22-23 March 2019; Volume 1, pp. 1-5.

19. Silva, C.E.D.A.E.; Bascopé, R.T.; Oliveira, D.S. Three-phase power factor correction rectifier applied to wind energy conversion systems. In Proceedings of the 23rd Annual IEEE Applied Power Electronics Conference and Exposition, Austin, TX, USA, 24-28 February 2008; pp. 768-773.

20. Nian, H.; Liu, J.; He, Y. Research on the unit power factor control of directly-driven PM wind generator. In Proceedings of the IEEE International Conference on Electrical Machines and Systems, Wuhan, China, 17-20 October 2008; pp. 2311-2315.

21. Ma, Y.; Sun, X.; Chai, J. Synchronous PI current control technique for three-phase PFC rectifier for PMSG wind generation system. In Proceedings of the 2nd International Symposium on Power Electronics for Distributed Generation Systems, Hefei, China, 16-18 June 2010; pp. 236-239.

22. Teodorescu, R.; Liserre, M.; Rodríguez, P. Grid Converters for Photovoltaic and Wind Power Systems; John Wiley and Sons: Chichester, UK, 2011; pp. 52-63.

Publisher's Note: MDPI stays neutral with regard to jurisdictional claims in published maps and institutional affiliations. 